Fernanda Carbonario

\title{
Efeitos de um programa \\ fisioterapêutico na melhora da \\ sintomatologia \\ e qualidade de vida \\ de pacientes com fibromialgia
}

São Paulo

2006 
Fernanda Carbonario

\section{Efeitos de um programa \\ fisioterapêutico na melhora da \\ sintomatologia \\ e qualidade de vida \\ de pacientes com fibromialgia}

Dissertação apresentada à Faculdade de Medicina da Universidade de São Paulo para obtenção do título Mestre.

Área de concentração: Postura, Movimento e Ação Humana

Orientadora: Profa Dra. Amélia Pasqual Marques

São Paulo

2006 
"A verdadeira função do homem é viver, não apenas existir."

(Jack L ondon) 


\section{Agradecimentos}

A Prof. Dra. Amélia Pasqual Marques, pela orientação, dedicação e carinho. Sua disposição e amor pela pesquisa contagiam e inspiram a todos que vivenciam a Fisioterapia.

Aos meus pais, Ana Maria e Antonio, ao meu marido, Reinaldo, e ao meu irmão, Alexandre, pelo amor e apoio. Minha admiração e amor a vocês.

A empresa BIOSET - que concedeu o equipamento utilizado nesse trabalho.

A amiga Luciana Akemi e Gilberto, pela amizade, dedicação e confiança.

Ao Prof. Carlos Alberto de Bragança Pereira, pelos ensinamentos compartilhados e colaboração na análise estatística.

Aos colegas de Pós-graduação, em especial a Ana, por dividirem os aprendizados e pelo seu carinho.

Aos meus colegas da Unidade de Reabilitação do Hospital Geral de Pirajussara, em especial as colegas, Adriana, Selma e Stella, pela compreensão e amizade.

As mulheres participantes da pesquisa, pela disposição, confiança, paciência e tempo investidos no tratamento.

Ao Hospital Geral de Pirajussara, em especial ao Dr. Jorge Salomão e ao Sr. José Carlos, pela confiança depositada em mim.

A Universidade de São Paulo, que traz orgulho a todos que fazem parte de sua existência.

Obrigado. 


\section{ÍNDICE}

\section{RESUMO}

\section{SUMMARY}

\section{INTRODUÇÃO}

01

Justificativa

17

Objetivo geral

18

Objetivos específicos

2. MATERIAL E MÉTODO 19

Casuística

Situação 21

Material

21

Procedimento

A. Avaliação e Sessão educativa

B. Intervenção

27

Análise estatística

3. RESULTADOS

Características da amostra

30

Comparação dos dados iniciais e finais

Comparação entre os grupos

37

4. DISCUSSÃO

5. CONCLUSÃO

49

6. REFERÊNCIAS BIBLIOGRÁFICAS

7. ANEXOS

ANEXO 1 - Autorização da Comissão de Ética FMUSP

ANEXO 2 - Protocolo de Avaliação

ANEXO 3 - Questionário Do Impacto Da Fibromialgia (FIQ) 59

ANEXO 4 - Questionário SF-36

60

ANEXO 5 - Questionário de Dor de McGill

64

ANEXO 6 - Termo de Consentimento Livre e Esclarecido 65

ANEXO 7 -Cartilha de Orientação as Pacientes com Fibromialgia 68 


\section{Resumo}

Fibromialgia é uma síndrome reumática caracterizada por dor musculoesquelética difusa e crônica, sítios dolorosos específicos à palpação (tender points), freqüentemente associados a fadiga, distúrbios do sono, rigidez matinal, ansiedade, depressão e, em alguns casos, dispnéia. Devido ao quadro doloroso e ao caráter crônico, a síndrome geralmente tem impacto negativo na qualidade de vida dos pacientes. O objetivo do presente estudo foi avaliar a eficácia de um programa fisioterapêutico (16 sessões) composto de orientação educacional, terapia com corrente de estimulação elétrica nervosa transcutânea (TENS) e exercícios aeróbicos e de alongamento muscular, sobre a sintomatologia e qualidade de vida de pacientes com fibromialgia. Foram selecionadas 28 mulheres com diagnóstico de fibromialgia originárias do ambulatório da Unidade de Reabilitação do Hospital Geral de Pirajussara da Universidade Federal de São Paulo, que foram submetidas a avaliação antes e após o programa fisioterapêutico. A dor foi avaliada pela escala visual analógica (VAS), questionário de dor de McGill e dolorimetria dos tender points; a flexibilidade, pelo índice terceiro-dedo-solo; e a qualidade de vida, pelos questionários Fibromyalgia Impact Questionnaire (FIQ) e Medical Outcomes Study 36-item Short-Form Health Survey (SF-36). As pacientes foram distribuídas em dois grupos (G1 e G2), ambos com 14 indivíduos. Os dois grupos receberam uma sessão educativa e 16 sessões de tratamento com exercícios de alongamento e condicionamento físico; além disso, G2 também recebeu aplicação de TENS em quatro tender points (trapézio e supraespinhoso). Os dados das avaliações foram tratados estatisticamente, com nível de significância $p=0,05$. A comparação das avaliações inicial e final mostrou que ambos os grupos apresentaram melhora na flexibilidade (diferença estatisticamente significante no índice terceiro-dedo-solo de $\mathrm{p}=0,00$ e 0,04 , respectivamente para G1 e G2) e redução da dor, segundo as respostas ao Questionário de McGill ( $\mathrm{p}=0,03$ e 0,01, para G1 e G2); G2 também apresentou redução da dor na VAS $(\mathrm{p}=0,00)$ e no limiar de dor em dois dos tender points que receberam TENS (trapézio E e supraespinhoso D). Quanto à qualidade de vida, G1 relatou melhora no SF-36 ( $\mathrm{p}=0,02)$ e G2 no FIQ $(\mathrm{p}=0,00)$. Não houve diferença estatisticamente significante entre os grupos, exceto para o limiar de dor no tender point supraespinhoso $\mathrm{E}(\mathrm{p}=0,02)$. Conclui-se que o programa fisioterapêtico proposto foi eficaz na redução da dor, melhora da flexibilidade e da qualidade de vida das pacientes, e que a aplicação da TENS pode ter interferido positivamente nos resultados do tratamento. A abordagem educativa e o bom relacionamento terapeutapaciente podem contribuir para mudanças de hábitos das pacientes e torná-las mais ativa no tratamento. 


\section{Abstract}

Fibromyalgia is a rheumatic syndrome characterised by diffuse muscle pain, low pain threshold at tender points, and a series of associate symptoms such as fatigue, sleep disturbance, anxiety, morning stiffness, and dyspnea in some cases; due to its being chronic, the constant pain has often a negative impact on patients' quality of life. The aim of the present study is to assess the effectiveness of an eight-week physical therapy program made up of educational guidance, transcutaneous electrical nerve stimulation (TENS), and aerobic and stretch exercises, on to fibromyalgia patients' symptoms and quality of life. Subjects were 28 women with fibromyalgia diagnosed by the Rehabilitation Unity of the Pirajussara General Hospital of the Federal University of São Paulo. They underwent assessment before and after treatment. Pain was evaluated by the Visual Analogical Scale (VAS), the McGill Pain Questionnaire, and by dolorimetry at tender points; flexibility was assessed by means of the fingertip-to-floor test; and quality of life, by the Fibromyalgia Impact Questionnaire (FIQ) and the Medical Outcomes Study 36-item Short-Form Health Survey (SF-36). Patients were divided into two groups (G1 and G2), both with 14 subjects each.. Both groups attended an educational session and 16 sessions of stretch and aerobic exercises; besides these, G2 patients also received TENS applications on four tender points (left and right trapezius and supraspinatus). Data collected at initial and final assessments were statistically treated, with significance level set at $p=0,05$. The comparison between the two assessments shows that both groups presented improved flexibility (with a statistically significant difference of $\mathrm{p}=0.00$ and 0.04 for G1 and G2, respectively, at the fingertip-to-floor test), and pain reduction according to the McGill Questionnaire ( $\mathrm{p}=0.03$ and 0.01 for $\mathrm{G} 1$ and $\mathrm{G} 2$ ); G2 also indicated pain reduction at the VAS $(\mathrm{p}=0.00)$ and at the pain threshold on two treated tender points ( $\mathrm{L}$ trapezius and R supraspinatus). As to quality of life, G1 reported improvement at the SF-36 $(\mathrm{p}=0.02)$ and G2 at the FIQ $(\mathrm{p}=0.00)$. No statistically significant differences were found between the two groups, except for the pain threshold on the left supraspinatus tender point $(\mathrm{p}=0,02)$. The proposed physical therapy program thus proved effective in reducing patients' pain and improving flexibility and quality of life; TENS application may have had a positive effect on treatment results. The educational approach as well as the good therapist-patient relationship may well contribute to patients changing habits and taking a more active part in their treatment. 


\section{INTRODUÇÃo}

"Fibromialgia é uma síndrome de dor difusa e crônica, caracterizada pela presença de pelo menos 11 dos 18 pontos anatomicamente específicos chamados de tender points, dolorosos à palpação de cerca de $4 \mathrm{kgf} / \mathrm{cm}^{2} " 1$.

O estabelecimento dos critérios básicos de classificação da fibromialgia pelo comitê do Colégio Americano de Reumatologia (ACR), liderado por Wolfe em 1990, impulsionou os estudos a respeito desta síndrome (Quadro 1 ).

Dor difusa: dor no lado esquerdo do corpo, dor no lado direito do corpo, dor acima da linha da cintura e dor abaixo da linha da cintura. Em adição, uma dor no esqueleto axial (segmento cervical, torácico ou lombar da coluna vertebral) deve estar presente. A dor difusa deve estar presente pelo menos por três meses.

Dor à palpação, com uma pressão de aproximadamente $4 \mathrm{kgf} / \mathrm{cm}^{2}$, em pelo menos 11 dos 18 tender points (descritos abaixo):
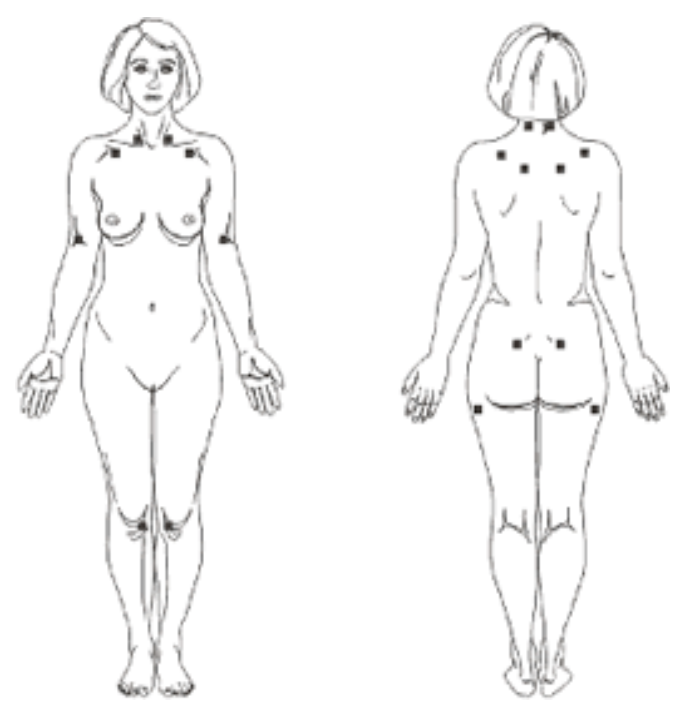

(1 e 2) Occipital: inserção dos músculos suboccipitais;

(3 e 4) Cervical baixa: anteriormente, entre os processos transversos de C5-C7;

(5 e 6) Trapézio: ponto médio das fibras superiores do músculo trapézio;

(7 e 8) Supraespinhal: inserção do músculo supraespinhal, acima da espinha da escápula próximo ao ângulo medial;

(9 e 10) Segunda articulação costocondral: lateral e superiormente à articulação;

(11 e 12) Epicôndilo lateral: 2cm distalmente ao epicôndilo;

(13 e 14) Glúteo: quadrante superior e lateral das nádegas;

(15 e 16) Trocânter maior: posterior à proeminência trocantérica;

(17 e 18) Joelho: coxim gorduroso medial, próximo à linha articular

Quadro 1 - Critérios de classificação da fibromialgia estabelecidos em 1990 pelo Colégio Americano de Reumatologia ${ }^{2}$. 
Durante o desenvolvimento dessa teoria, foi levantada a hipótese de que $a$ priori, a localização e distribuição da dor, os sintomas de rigidez matinal, fadiga, distúrbio do sono e o número, localização e escore dos tender points poderiam diferenciar efetivamente os pacientes dos sujeitos controles. Os resultados mostraram que os critérios proporcionavam os melhores índices de sensibilidade $(88,4 \%)$, especificidade $(81,1 \%)$ e acurácia $(84,9 \%)$, em relação a outras doenças reumatológicas. Deste modo, poderiam ser apropriados tanto em investigações clínicas ou epidemiológicas, assim como no diagnóstico da própria fibromialgia.

Os sintomas de rigidez, fadiga e distúrbio do sono estavam presentes em mais de $75 \%$ dos pacientes; entretanto, a presença simultânea destes três sintomas referidos poderia não estar necessariamente presente nos pacientes com fibromialgia (1). Os resultados deste estudo mostraram que os critérios poderiam ser aplicados para ambos os casos em que a fibromialgia ocorria concomitantemente a outras doenças (chamada de fibromialgia secundária) ou não-concomitante (fibromialgia primária): sendo então abolida distinção entre fibromialgia primária e secundária. Assim, de acordo com os critérios, a presença de outra doença não excluía o diagnóstico de fibromialgia.

Estes critérios foram validados em uma população brasileira por Haun ${ }^{3}$ que em seu estudo questionou se diferenças étnicas, econômicas, culturais e sociais poderiam influenciar as manifestações clínicas e reconhecimento da síndrome. Utilizando a metodologia do trabalho do comitê do ACR, os resultados deste estudo mostraram que a combinação de dor difusa e nove ou mais pontos dolorosos dos 18 possíveis apresentou sensibilidade de 93,2\%, especificidade de 92,1\% e acurácia de 96,6\%, sendo os melhores critérios para esta população. Os sintomas de fadiga e distúrbio do 
sono ocorreram em mais de $80 \%$ dos pacientes, como encontrado no estudo do comitê do ACR; entretanto, não foi encontrada diferença estatística no sintoma de rigidez em relação aos sujeitos controles, ao contrário do estudo de Wolfe ${ }^{1}$.

Muitas discussões têm sido geradas em virtude destes critérios diagnósticos contarem primariamente com características subjetivas, como a dor. Neste ínterim, não há exames laboratoriais ou radiológicos que confirmem ou excluam o diagnóstico, pois os pacientes não apresentam alterações evidentes de órgãos ou sistemas, embora refiram elevados níveis de dor, fadiga e outros sintomas associados semelhantes aos pacientes com outras doenças mas com uma fisiopatologia evidente como, por exemplo, a artrite reumatóide ${ }^{4}$.

Wolfe et al. ${ }^{5}$ realizaram um trabalho nos Estados Unidos, mostrando que a prevalência da fibromialgia na população acima de 18 anos de idade, é de 2,0\% para ambos os sexos; $3,4 \%$ para o sexo feminino e; $0,5 \%$ para o sexo masculino. Os autores ainda verificaram maior prevalência em mulheres com idade acima de 50 anos.

A dor é o sintoma principal da fibromialgia. Entretanto, a literatura tem apresentado vários outros sintomas que podem acometer os pacientes com esta síndrome, entre eles estão: parestesia, dificuldade de memória, palpitação, tontura, sensação de inchaço, dor torácica, cefaléia crônica, ansiedade, depressão, irritabilidade, epigastralgia, dispnéia, enjôo, dificuldade de digestão, fenômeno de Raynauld, dismenorréia, cólon irritável e disfunção sexual; sendo suas ocorrências variadas entre os estudos ${ }^{1,6}$.

A complexidade das manifestações clínicas da fibromialgia tem sido relacionada à procura de muitos pacientes por médicos de diversas especialidades. 
Estes pacientes são muitas vezes submetidos a múltiplos exames complementares e têm recebido diversos rótulos diagnósticos. Tudo isto pode levar a condutas terapêuticas incorretas, agravando ainda mais o quadro clínico dos pacientes; assim, o primeiro desafio consiste no correto reconhecimento desta síndrome.

Apesar da etiologia e fisiopatologia da fibromialgia ainda serem desconhecidas, várias hipóteses têm sido apresentadas pela literatura. A dor muscular é o sintoma primário da fibromialgia. Alguns trabalhos avaliaram se esta síndrome poderia ser originária de uma alteração do sistema musculoesquelético. De acordo com a revisão bibliográfica de Simms et al. ${ }^{7}$, a maioria dos estudos sobre o tecido muscular de pacientes com fibromialgia não mostra evidências de alterações morfológicas significativas nos pacientes. Entretanto, outros trabalhos sugerem a presença de alterações metabólicas neste sistema. Esta alteração seria caracterizada pela diminuição do fluxo sanguíneo, levando a uma diminuição de oxigênio disponível para as fibras musculares e acarretando em um metabolismo celular anormal, como os níveis mais baixos de adenosinatrifosfato encontrados e clinicamente observados como a dor no músculo esquelético durante a realização de atividades. $^{8}$

Jeschonneck et al ${ }^{9}$ sugerem que uma vasoconstrição ocorre na pele sob os tender points, levando à hipótese de que estes pontos dolorosos na fibromialgia poderiam estar relacionados com uma hipóxia local. Os autores observaram em seu trabalho, com relação aos eritrócitos, um aumento da sua concentração, diminuição da sua velocidade e uma conseqüente diminuição do seu fluxo na pele sob os tender points; além da temperatura mais baixa nestes pontos comparativamente aos indivíduos controles. 
Ao se considerar a alteração da sensibilidade dolorosa como a principal manifestação clínica dos pacientes com fibromialgia, vários estudos têm sido realizados para demonstrar uma possível interação entre fatores ambientais e sistêmicos, confluindo para a presença da diminuição do limiar de dor, comum nesta síndrome. Este modelo é explicado através de uma interação entre fatores exógenos (por exemplo, fatores de estresse) e endógenos (por exemplo, uma disfunção neuroendócrina) em indivíduos predispostos geneticamente. Isto poderia levar a uma alteração da função do sistema nervoso central e da produção de neurotransmissores relacionados com a sensibilidade dolorosa anormal nestes pacientes ${ }^{10}$.

Os recentes estudos a respeito dos neurotransmissores voltam a atenção à serotonina. A serotonina tem papel na modulação da dor, agindo como um neurotransmissor inibitório da liberação de substância $\mathrm{P}$ pelos neurônios aferentes proveniente de um estímulo nociceptivo periférico. Os estudos mostram uma diminuição do nível de serotonina, além de seus precursores (triptofano) e metabólitos (acido 5-hidroxiindolacético) no soro sanguíneo dos pacientes com fibromialgia comparados a indivíduos controles. Esta alteração poderia explicar a amplificação da dor nestes pacientes. Além disso, sugere-se que o nível sangüíneo do ácido 5-hidroxiindolacético está diretamente relacionado com a qualidade do sono dos pacientes e, inversamente relacionado com o nível da substância $\mathrm{P}^{11}$.

Estudo de caráter experimental tem sido realizado para se avaliar a atividade da função cerebral em pacientes com fibromialgia. Através do auxílio da tomografia computadorizada por emissão de fóton único, foi observada uma diminuição do fluxo sanguiíneo em regiões cerebrais específicas (como o tálamo e o núcleo caudado) de pacientes comparados com indivíduos controles; sugerindo-se uma resposta anormal 
aos estímulos nociceptivos, como a hipersensibilidade a estímulos mecânicos, térmicos e químicos. Este trabalho levanta a hipótese da presença de alterações do funcionamento do sistema nervoso central que estaria relacionado com a diminuição do limiar de dor e com alterações da percepção da dor nos pacientes com fibromialgia ${ }^{12}$.

Outra hipótese muito debatida atualmente é a possível existência de um distúrbio funcional do sistema neuroendócrino, que poderia contribuir para o desenvolvimento de outros sintomas da fibromialgia além da dor, como a fadiga, distúrbio do sono e distúrbios psicológicos. O sistema neuroendócrino é responsável pela comunicação do sistema nervoso central com os demais sistemas corporais; através da integração de sinais do córtex e da periferia pelo hipotálamo, o qual é responsável pela liberação de hormônios para a glândula pituitária possuindo efeitos diretos sobre os demais tecidos corporais ${ }^{13}$.

Este distúrbio funcional do sistema neuroendócrino seria caracterizado por uma perturbação da resposta ao estresse normal. Um dos principais responsáveis pela coordenação das respostas físiológicas ao estresse mental ou físico é o eixo hipotálamo-hipófise-adrenal. Alguns estudos sugerem haver uma disfunção deste eixo em pacientes com fibromialgia. Estudos nesta área sugerem que pacientes com fibromialgia exibem uma deficiência da função do hormônio de liberação da corticotropina produzido pelo hipotálamo. Este hormônio seria responsável pela estimulação do eixo hipotálamo-hipófise-adrenal e do sistema nervoso simpático, além de inibir as vias ascendentes de dor ${ }^{13}$.

Um estudo em dois pacientes com fibromialgia que foram submetidos a tratamento devido à deficiência de alfa 1-antitripsina (A1AT), substância que tem 
altas concentrações séricas e modula muitas reações antiinflamatórias, mostrou que a infusão intravenosa de A1AT humana purificada, controlou também os sintomas da fibromialgia. Alguns estudos mostram que marcadores inflamatórios encontrados no sangue e/ou em biópsia muscular tem descrições anormais em pacientes com fibromialgia. Como a A1AT pode inibir a maioria dos mediadores inflamatórios, essas observações sugerem que a síndrome da fibromialgia pode estar relacionada a um processo inflamatório, possivelmente devido ao desequilíbrio entre substâncias inflamatórias e antiinflamatórias nos tecidos moles corporais ${ }^{14}$.

Outro estudo concluiu que a ativação das células Tpodem ser defeituosas em pacientes com fibromialgia, o que pode sugerir um envolvimento em potencial do sistema imune na patogênese da síndrome ${ }^{15}$.

Apesar do esforço para determinar a etiopatogenia da fibromialgia, o seu tratamento continua sendo um desafio para os profissionais de saúde.

A principal ênfase está centrada na melhora do controle da dor e no aumento ou manutenção das habilidades funcionais efetivamente em casa ou no trabalho, seguida da redução de outras manifestações que trazem sofrimento a estes pacientes.

As respostas terapêuticas incluem a terapia medicamentosa e a nãomedicamentosa, esta última alternativa terapêutica abrange a fisioterapia e a psicologia.

Em relação à terapia medicamentosa, a literatura cita o emprego de medicamentos antidepressivos, relaxantes musculares, analgésicos e antiinflamatórios. Os estudos nesta área apresentam resultados favoráveis dos medicamentos antidepressivos e dos relaxantes musculares sobre a melhora da dor; 
porém não há dados que demonstrem a eficácia dos analgésicos e antiinflamatórios no tratamento destes pacientes ${ }^{16}$.

Além da terapia medicamentosa, a fisioterapia tem sido muito preconizada no tratamento da fibromialgia ${ }^{17}$. Esta desempenha um papel importante na diminuição das conseqüências da síndrome sobre as atividades de vida diária dos pacientes. Porém, a literatura mostra que a maioria dos estudos nesta área está voltada para os programas de exercícios físicos demonstrando resultados benéficos ${ }^{19}$.

Os exercícios físicos de baixa intensidade ou aqueles em que o paciente é capaz de identificar o limite de seu esforço e dor, parecem ser os mais efetivos. Os mais citados são os exercícios aeróbicos, como a caminhada, exercícios de alongamento muscular, exercícios aquáticos, bicicleta e esteira ${ }^{19,20,21,22}$.

Os exercícios de alongamento muscular também parecem desempenhar um papel positivo no tratamento da fibromialgia. Entretanto estão freqüentemente associados a outros recursos terapêuticos, como exercícios aeróbicos ${ }^{19,23}$ ou a eletroterapia $^{24}$.

Marques et al. ${ }^{20}$ avaliaram o efeito de exercícios de alongamento muscular em pacientes com fibromialgia e observaram melhora significativa dos sintomas de dor destas pacientes. Também Matsutani ${ }^{25}$ verificou que os exercícios de alongamento assim como as orientações educativas têm um papel importante na melhora da qualidade de vida dos pacientes com fibromialgia, porém ao testar a terapia com LASER não observou resultado estatisticamente significante.

Outros recursos fisioterapêuticos, como a estimulação elétrica nervosa transcutânea ${ }^{24}$ e o relaxamento por biofeedback ${ }^{26}$ parecem mostrar um papel importante terapêutico complementar. 
Por vezes, a dor nos pacientes com fibromialgia se apresenta tão intensa que interfere no trabalho, nas atividades de vida diária e na qualidade de vida ${ }^{5}$.

Martinez et al. ${ }^{27}$ avaliaram a qualidade de vida de pacientes com fibromialgia através do questionário SF-36 e compararam com indivíduos controles. Constataram que a qualidade de vida das pacientes era significativamente inferior, pois estas apresentavam maior limitação funcional nas atividades de vida diária, limitação física relacionada com o trabalho, impacto de aspectos psicológicos (como ansiedade e depressão) no bem-estar, maior intensidade de dor e de sua interferência nas atividades de vida diária, menor vitalidade, menor integração na sociedade e pior bem-estar psicológico.

A qualidade de vida dos pacientes com fibromialgia também tem sido comparada com a de pacientes com outras condições crônicas.

Martinez et al. ${ }^{4}$ compararam a qualidade de vida de pacientes com fibromialgia e artrite reumatóide. Constataram que ambas as condições causavam um impacto negativo na qualidade de vida dos pacientes, sendo comparativamente similares. Além disso, verificaram que 50\% dos pacientes com fibromialgia e 62,5\% dos pacientes com artrite reumatóide tinham parado de trabalhar em virtude da doença.

Bennett ${ }^{28}$ discute a avaliação da capacidade funcional dos pacientes com fibromialgia pelos profissionais de saúde. O ator afirma que a avaliação da real incapacidade funcional é difícil de se realizar em estados de dor crônica como a fibromialgia, porque está baseada somente na autopercepção do paciente em ser capaz de realizar as atividades usuais. Geralmente, parece não haver uma concordância entre os achados do exame clínico e aquilo que os pacientes alegam. 
Isso ocorre, pois a dor é uma sensação puramente subjetiva e, a dor crônica não pode ser compreendida em termos do modelo de doença relacionada com uma patologia com lesão tecidual.

White et al. ${ }^{29}$ realizaram um estudo de 100 casos de pacientes com diagnóstico de fibromialgia no Canadá, a fim de identificar os fatores que prediziam a incapacidade para o trabalho. Verificaram que $87 \%$ dos pacientes relataram que a "dor" era a maior causa de incapacidade para o trabalho, seguida da "fadiga" (80\%) e "fraqueza" (73\%). Além disso, 74\% dos pacientes relataram ter reduzido o nível de suas atividades usuais em virtude dos problemas de saúde.

A utilização de um meio físico eficiente como alternativa ao alívio da dor é de extrema importância, pois amenizaria o impacto desse sintoma sobre a qualidade de vida das pessoas com fibromialgia A Fisioterapia dispõe de inúmeros recursos terapêuticos para proporcionar analgesia, sendo que um dos mais utilizados é a estimulação nervosa elétrica transcutânea (TENS).

O desenvolvimento da TENS está baseado no trabalho de Melzack e Wall ${ }^{30}$ que construiu a teoria da comporta para explicar o controle e a modulação da dor.

A modulação da transmissão da dor mediante a alteração do input aferente à medula espinhal é conhecida como teoria da comporta (ou portal) do controle da dor, que foi estabelecida por Melzack e Wall em 1965. Nesta teoria, a ativação de axônios mielinizados de grande diâme tro na periferia aumenta a intensidade de inibição que atua sobre as células T na medula espinal, via células da substância gelatinosa (SG). Embora certo nível de input excitatório às células $\mathrm{T}$ ainda esteja presente (vias aferentes nociceptivas), este input será efetivamente abolido pelo nível mais elevado de inibição promovido pelas células SG. Diz-se que o input inibitório causado pela 
estimulação dos aferentes mecanossensíveis de grande diâmetro "fecha a comporta" para a transmissão da dor através das células $\mathrm{T}$ na medula espinal ${ }^{31}$. A Figura 1 mostra o equilíbrio entre as influências excitatórias e inibitórias sobre a célula $\mathrm{T}$ que determina a transmissão da dor até os centros superiores. Neste caso a maior intensidade de atividade inibitória, gerada pela ativação de aferentes de grande diâmetro supera a intensidade da atividade excitatória, produzida pela ativação de nociceptores ${ }^{31}$.

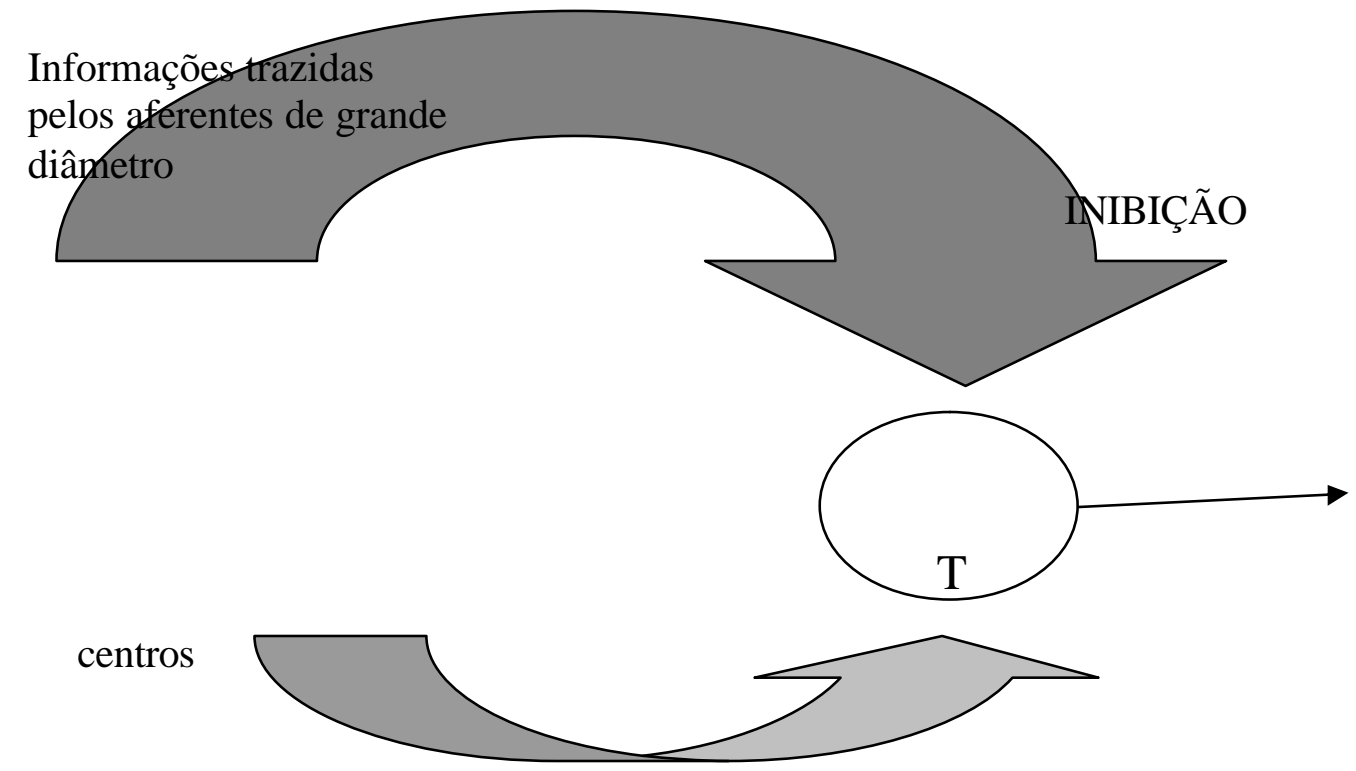

superiores

Informações nociceptoras EXCITAÇÃO

\section{Figura 1 -Teria da Comporta}

(A seta escura representa a maior intensidade de atividade inibitória e a seta clara, a intensidade da atividade excitatória ${ }^{31}$.) 
Esta teoria tem implicações importantes para o tratamento da dor na Fisioterapia. Qualquer técnica que envolva a ativação de aferentes mecanossensíveis de grande diâmetro, tem um potencial de modulação da transmissão da dor na medula espinal. As técnicas como a massagem, manipulação da articulação, tração e compressão, estimulação térmica e eletroterapia, têm a capacidade de produzir informações sensitivas a partir de aferentes de baixo limiar, que podem, em última análise, inibir a transmissão da dor na medula espinal mediante o "fechamento do portão", isto é, pela inibição da excitabilidade das células T via células da substância gelatinosa.

A TENS pode ser utilizada na estimulação direta destes aferentes numa área e voltagem apropriadas, que irão influenciar a transmissão da dor nos segmentos espinais relevantes. Portanto, tanto o terapeuta como os pacientes podem ter controle sobre a modulação da dor, tendo a possibilidade de ajustar os níveis desta modulação em qualquer momento.

A TENS é uma corrente de baixa frequiência, quando comparada a todo o espectro das freqüências da corrente elétrica disponíveis para usos terapêuticos. Essa é composta da unidade geradora de corrente elétrica, fios elétricos e eletrodos. Os aparelhos de TENS podem ter um ou dois canais, sendo que cada canal permite como parâmetro uma só amplitude para o par de eletrodos. Os parâmetros são: amplitude, forma da onda, estímulo adequado, potenciais de ação sensitivos, freqüência de pulso, estimulação de freqüência variável por rajadas contínuas. Os parâmetros das unidades mudam de acordo com o fabricante, porém todos produzem uma forma de onda pulso, com freqüências de pulsos de 1 até $150 \mathrm{~Hz}$, duração do pulso de 0,040 até $0,300 \mathrm{~ms}$, e intensidades entre 0 e $60 \mathrm{~mA}^{32}$. 
Existem vários modos de estimulação com a TENS e um dos modos utilizados para induzir um período curto de eletroanalgesia durante um procedimento desconfortável é a TENS breve intenso. Os eletrodos são colocados em volta ou próximo ao local de dor, o parâmetro do pulso é colocado no máximo (normalmente cerca de $150 \mathrm{~Hz})$ e a amplitude é movida até induzir fasciculações musculares fortes e intermitentes. A estimulação pode ser aplicada por um tempo de 15 minutos antes de a fadiga muscular requerer um período de descanso. Após alguns minutos, a estimulação pode ser retomada. A analgesia resultante permite um alívio durante um procedimento desconfortável como debridamento de feridas, trabalhos odontológicos, massagem por fricção ou mobilização articular ${ }^{33}$.

A TENS é um recurso analgésico muito utilizado. Lindsay ${ }^{34}$ pesquisou 208 clínicos canadenses e verificou que era o recurso analgésico mais utilizado entre os clínicos mais antigos e proprietários de clínicas privadas de Fisioterapia.

Diversas pesquisas com a TENS foram realizadas, porém os parâmetros e o tempo de aplicação nem sempre são mostrados. Também os resultados são controversos, ora provando que a corrente é eficaz e ora demonstrando-se igual ao placebo. Na literatura está claro o efeito analgésico desta estimulação que é explicado pela teoria da comporta, porém os estudos experimentais nem sempre corroboram com isso, tornando-se importante saber quais os parâmetros utilizados e o tempo de aplicação. Por exemplo, alguns estudos mostraram que o tempo de aplicação da corrente é importante para obtenção do efeito de analgesia e muitas vezes recomendou-se o uso de longa duração do aparelho, sendo necessária aplicação do mesmo no domicílio. Nos Quadros 2 e 3 são encontrados estudos que utilizaram a TENS como forma de tratamento. 
Chabal ${ }^{35}$ analisou a dor crônica em 376 pacientes e percebeu que o uso prolongado da TENS reduziu o uso de medicamento para a dor e os custos para tratamento da dor e diminuiu as complicações relacionadas ao uso de medicamentos.

Gashu ${ }^{24}$ utilizou a TENS em quinze pacientes com fibromialgia e obteve diminuição do limiar de dor nos tender points.

Além dos efeitos analgésicos, a TENS foi utilizada por Sherry ${ }^{36}$ que analisou 20 pacientes sem patologia conhecida e verificou um aumento do fluxo sanguíneo local durante e após aplicação de TENS. 


\begin{tabular}{|c|c|c|}
\hline $\begin{array}{l}\text { Referência } \\
\text { (primeiro autor e ano) }\end{array}$ & Diagnóstico & Resultado \\
\hline Cheing $2002^{37}$ & $\begin{array}{l}\text { Osteoartrose de joelho } \\
n=62\end{array}$ & ? Igual ao placebo \\
\hline Rushton, $2002^{38}$ & Dor moderada & $\begin{array}{l}\text { Provou ser seguro e eficaz para analgesia em metade } \\
\text { dos pacientes dos estudos analisados }\end{array}$ \\
\hline Gashu, $2001^{24}$ & $\begin{array}{l}\text { Fibromialgia } \\
\mathrm{n}=15\end{array}$ & Auxiliou no alívio da dor \\
\hline Limoge, $1999^{39}$ & Dor & $\begin{array}{l}\text { ? É efetivo se os caminhos de condução } \\
\text { estiverem preservados }\end{array}$ \\
\hline Lampl, $1998^{40}$ & $\begin{array}{l}\text { Dor crônica de várias } \\
\text { Origens } \\
n=482\end{array}$ & $\begin{array}{l}\text { Elaboração de um Escore Prognóstico para seleção efetiva } \\
\text { uso do T.E.N.S. } \\
\text { ? Validação desse Escore com } n=99\end{array}$ \\
\hline Kruger, $1998^{41}$ & $\begin{array}{l}\text { Dor miofascial } \\
\mathrm{n}=10\end{array}$ & ? Não ajudou no alívio da dor \\
\hline Fedorczk, $1997^{42}$ & $\begin{array}{l}\text { Condições músculoes- } \\
\text { queléticas das mãos e } \\
\text { membros superiores }\end{array}$ & $\begin{array}{l}\text { ? Não conclusivo (pouca qualidade do material } \\
\text { científico publicado) }\end{array}$ \\
\hline Stone, $1997^{43}$ & $\begin{array}{l}\text { Cervicalgia e Dor de cabeça tensional } \\
\mathrm{n}=81\end{array}$ & $\begin{array}{l}\text { T.E.N.S. associado a outras técnicas foi seguro e eficaz, porém } \\
\text { não afetou os triggers points }\end{array}$ \\
\hline Bassan, $1995^{44}$ & $\begin{array}{l}\text { Fibromialgia em criança } \\
\mathrm{n}=1\end{array}$ & $\begin{array}{l}\text { ?.E.N.S. associado a medicação mostrou } \\
\text { bom resultado[no alívio da dor }\end{array}$ \\
\hline
\end{tabular}

Quadro 2 - Estudos que utilizaram TENS. 


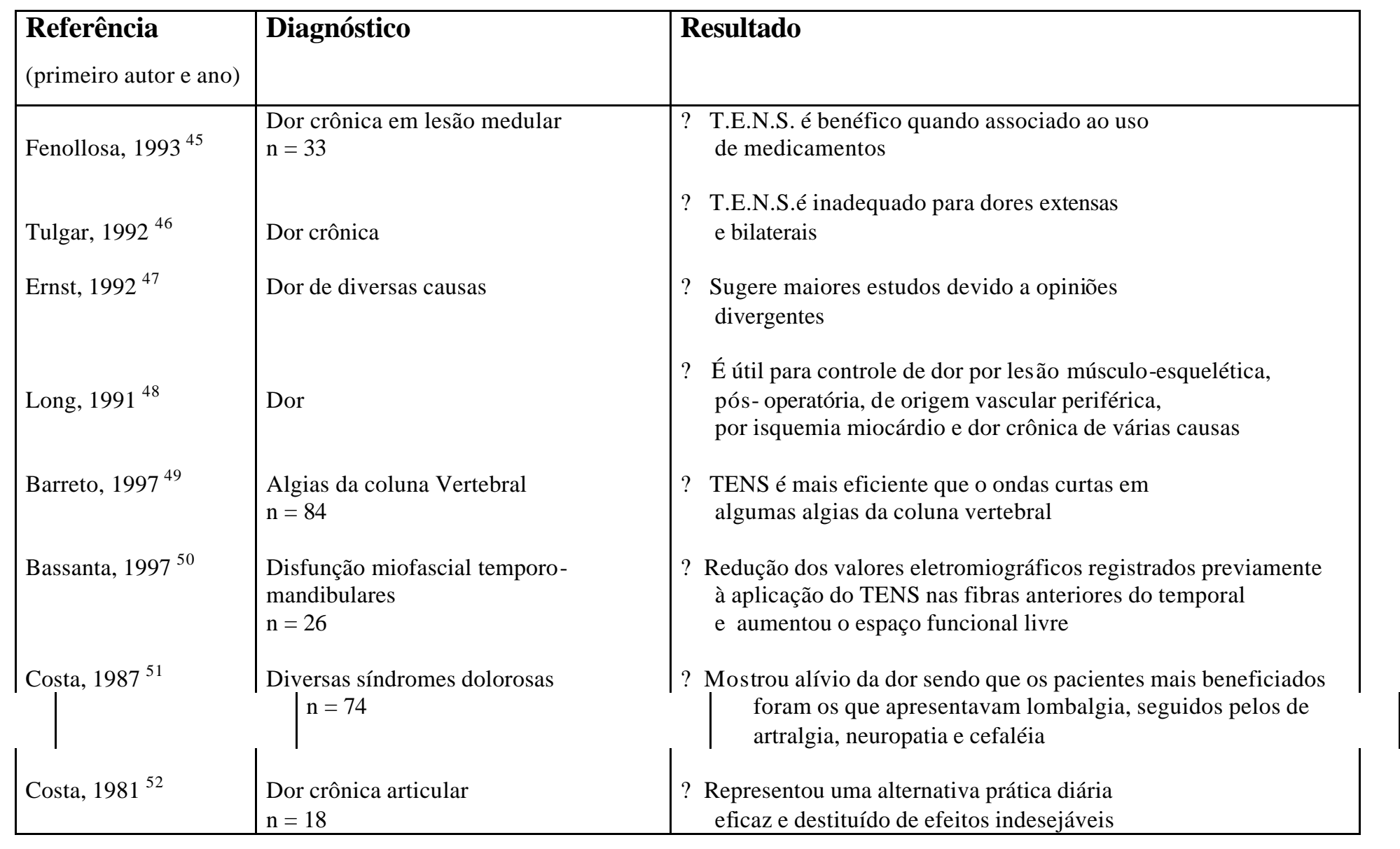

Quadro 3 - Estudos que utilizaram TENS. 


\section{Justificativa}

É fundamental encontrar alternativas eficazes de tratamento que objetivem amenizar o impacto da fibromialgia sobre a qualidade de vida dos pacientes.

O quadro de dor difusa e crônica associado à presença de pontos sensíveis pelo corpo (tender points), além de outros sintomas, é responsável pela má qualidade de vida em pacientes com fibromialgia quando comparada a indivíduos saudáveis, conforme apontado pela literatura.

Visto que os pacientes apresentam esta condição crônica (por meses ou anos) causando-lhes prejuízo nas atividades de vida diária, acredita-se que o alongamento muscular e exercícios aeróbicos possam beneficiá-los com melhora da qualidade de vida. A literatura aponta a TENS como uma alternativa para analgesia no local de aplicação e adjacências e um estudo mostra que há também efeito vascular no local de aplicação. Pacientes com fibromialgia apresentam diminuição do limiar de dor nos tender points, assim um recurso fisioterapêutico analgésico local nestes pontos poderia também beneficiá-los no alívio da dor.

Deste modo, o tratamento fisioterapêutico através da associação de exercícios de alongamento muscular, exercício aeróbico e orientação educativa com um recurso analgésico local pode ser uma das alternativas de tratamento que vise minimizar o impacto da sintomatologia desta síndrome e promover a melhora da qualidade de vida desses indivíduos. 


\section{Objetivo geral}

Avaliar a eficácia de um programa de tratamento fisioterapêutico composto de: tratamento com TENS em quatro tender points (trapézio e supraespinhoso, bilateralmente), exercícios aeróbicos, exercícios de alongamento e orientação educativa sobre a sintomatologia e a qualidade de vida de pacientes com fibromialgia.

\section{Objetivos específicos}

a) Avaliar o efeito da terapia com TENS, como recurso complementar, sobre a dor e o limiar de sensibilidade dolorosa dos tender points de pacientes com fibromialgia (mensurado pela mudança na dolorimetria, da escala analógica visual da dor (VAS) e do questionário McGill);

b) Quantificar a mudança na qualidade de vida, mensurada pelo FIQ e pelo SF36, após submeter os sujeitos ao programa terapêutico;

c) Quantificar a mudança da flexibilidade, através do Índice terceiro dedo-solo. 


\section{Casuística e Método}

\section{Casuística}

Foram obtidos 34 pacientes com diagnóstico de fibromialgia segundo os critérios do Colégio Americano de Reumatologia, provenientes do Hospital Geral de Pirajussara da Sociedade Paulista para Desenvolvimento da Medicina/Universidade Federal de São Paulo (SPDM/UNIFESP).

Estes foram distribuídos randomicamente em dois grupos à medida que foram encaminhados ao serviço de fisioterapia: grupo G1 que realizou exercícios aeróbicos, alongamento e orientação e grupo G2 que realizou exercícios aeróbicos, alongamento, orientação e TENS.

A seleção foi realizada segundo os seguintes critérios de inclusão:

Mulheres; 2) Apresentar nível cognitivo suficiente para entender os procedimentos e acompanhar as orientações dadas; 3)Consentir em participar do estudo e assinar o Termo de Consentimento Pós-Informação.

Observaram-se as seguintes condições como critérios de exclusão: a) Uso de marcapassos; b) Cardiopatias ou disritmias; c) Presença de dor não diagnosticada; d) Epilepsia; e) Mulheres gestantes e f) Artrose importante.

A partir do total de 34 sujeitos com diagnóstico de fibromialgia incluídos nesse estudo, houve perda na amostra de dois sujeitos por apresentarem uma ou mais condições observadas nos critérios de exclusão e quatro sujeitos por abandonarem o tratamento, sendo que dois sujeitos pertenciam ao grupo G1 e dois sujeitos pertenciam ao grupo G2. A amostra está representada na Figura 2. A análise 
estatística foi baseada nos 28 sujeitos que concluíram o tratamento de fisioterapia, sendo que cada grupo terminou com 14 sujeitos.

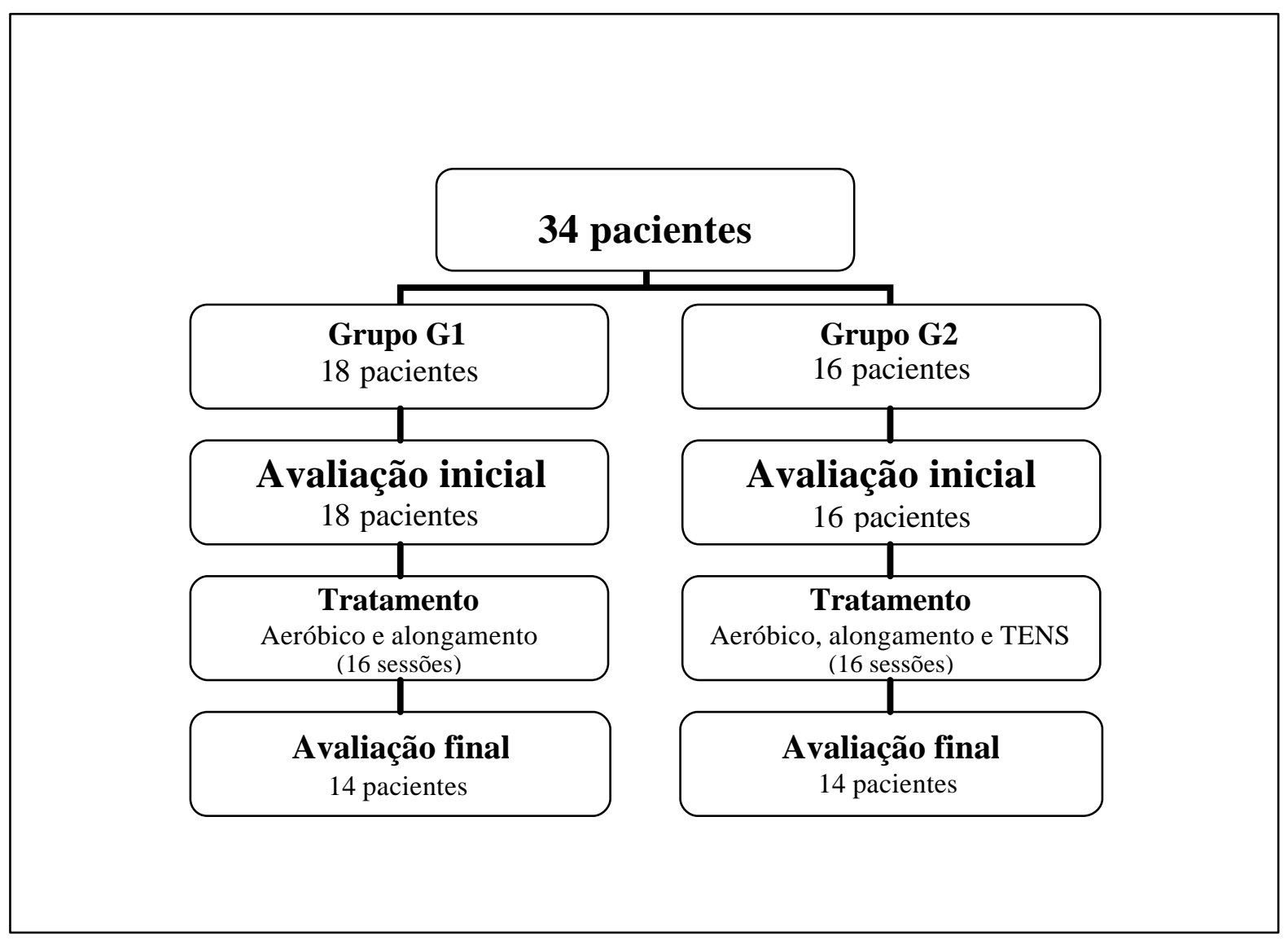

Figura 2 - Representação da amostra do total de 34 sujeitos selecionados para o estudo.

\section{Aprovação da Comissão de Ética}

Este trabalho foi aprovado pela Comissão de Ética para Análise de Projetos de Pesquisa (CAPPesq) da Diretoria Clínica do Hospital das Clínicas da Universidade de São Paulo em 10/03/2004 (Protocolo de Pesquisa nº 678/03) e após a aprovação foi encaminhado para o Comitê de Ética do Hospital Geral de Pirajussara que permitiu a coleta de dados nessa instituição (Anexo 1). 


\section{Situação}

O trabalho foi desenvolvido no ambulatório de Fisioterapia da Unidade de Reabilitação do Hospital Geral de Pirajussara da Sociedade para Desenvolvimento da Medicina/Universidade Federal de São Paulo (SPDM/UNIFESP).

\section{Material}

$\checkmark$ Protocolo de Avaliação - Fibromialgia (Anexo 2).

$\checkmark$ Índice terceiro dedo-solo. ${ }^{53}$

$\checkmark$ Fibromyalgia Impact Questionnaire (FIQ) ${ }^{54}$ (Anexo 3).

$\checkmark$ Medical Outcomes study 36-item Short-Form Health Survey (SF-36) ${ }^{55}$ (Anexo 4).

$\checkmark$ Questionário de dor McGill ${ }^{56}$ (Anexo 5).

$\checkmark$ Dolorímetro $^{57}$ (PTM - $10 \mathrm{Kg}$, área de $1 \mathrm{~cm}$ ) (Figura 3)

$\checkmark$ Lápis dematográfico preto (Dermatograph, Mitsubishi® 7600, Japão).

$\checkmark$ Fita métrica comum.

$\checkmark$ Aparelho TENS (Physiotonus III TENS, BIOSET®, Brasil) (Figura 4).

$\checkmark$ Bicicleta ergométrica (Carcikle, Carci®, Brasil) (Figura 5).

$\checkmark$ Cartilha de orientações, publicada por Matsutani et al. ${ }^{24}$ (Anexo 6).

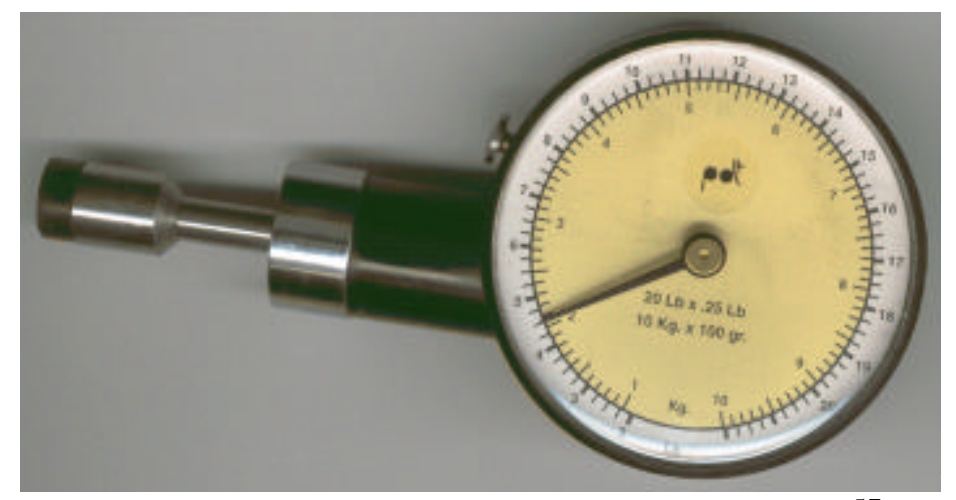

Figura 3 - Dolorímetro desenvolvido por Fischer ${ }^{57}$ 


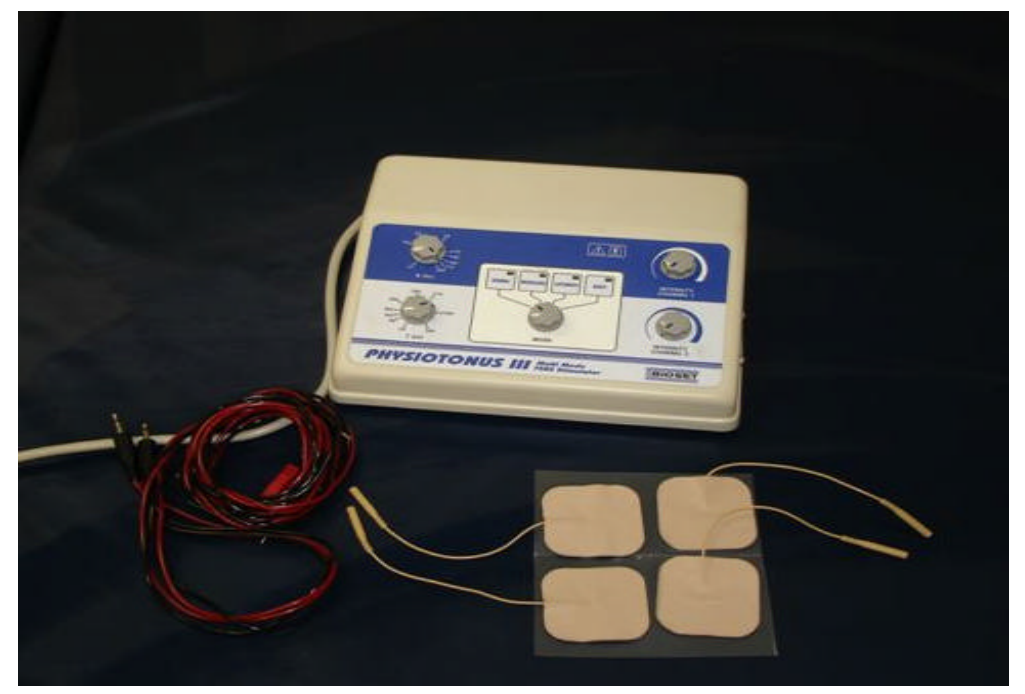

Figura 4 - Aparelho TENS (BIOSET®)

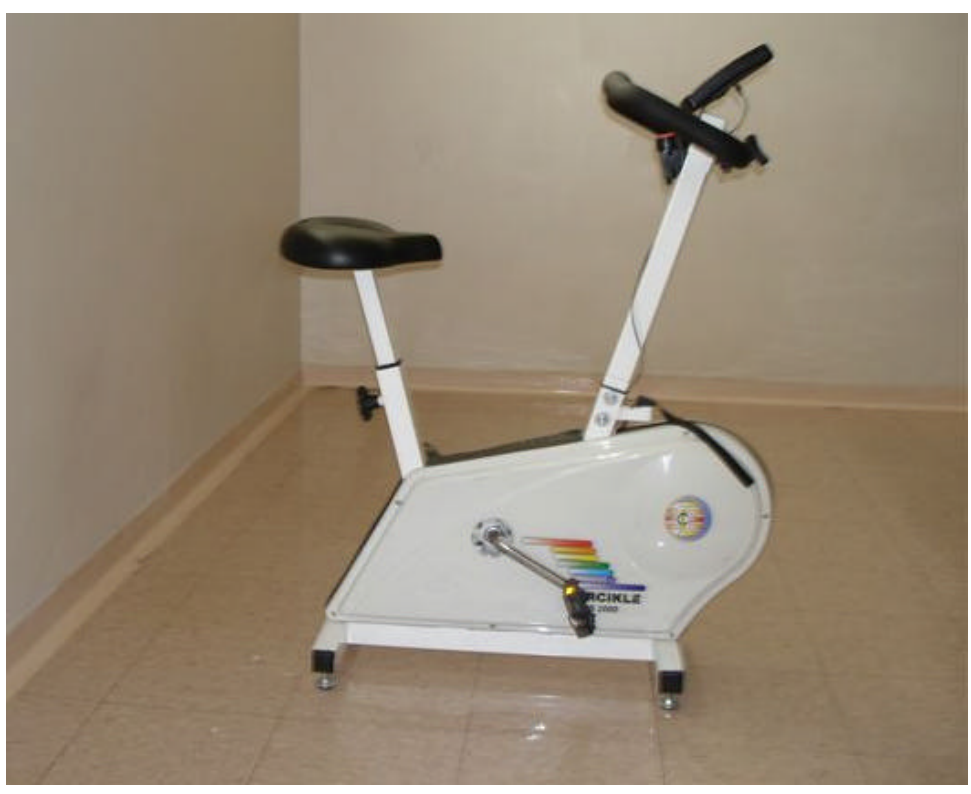

Figura 5 - Bicicleta ergométrica (Carci®) 


\section{Procedimento}

O procedimento seguiu os seguintes passos:

\section{A) Avaliação e Sessão educativa}

Todos os sujeitos dos dois grupos foram submetidos ao mesmo protocolo de avaliação (Anexo 2), que incluiu os seguintes aspectos:

Dados Pessoais: idade (em anos); massa (em quilogramas); altura (em metros); profissão; nível de escolaridade (sem estudo, $1^{\circ}$ grau incompleto, $1^{\circ}$ grau completo, $2^{\circ}$ grau incompleto, $2^{\circ}$ grau completo, universitário); estado civil.

História da dor: tempo de dor; local da dor em ordem decrescente de intensidade; período do dia em que a dor é mais intensa; fatores de melhora ou piora da dor; qualidade do sono; tipo de colchão e travesseiro.

Escala Analógica Visual da Dor (EVA) ${ }^{58}$. Avalia a intensidade da dor, consistindo de uma reta de 10 centímetros de comprimento desprovida de números, na qual há apenas indicação no extremo esquerdo de "ausência de dor" e no extremo direito de "dor insuportável". Quanto maior o escore, maior a intensidade da dor. A paciente foi instruída a marcar um ponto que indicava a intensidade da dor que sentia naquele momento.

Dolorimetria do limiar de dor dos 18 tender points ${ }^{1,2}$. O dolorímetro é um aparelho que avalia o limiar de sensibilidade dolorosa à pressão, possuindo uma extremidade aonde é aplicada uma pressão perpendicular à superfície da pele e um manômetro que registra esta pressão. A dolorimetria do limiar de dor dos tender 
points foi realizada de acordo com os critérios de classificação da fibromialgia do Colégio Americano de Reumatologia (1), seguindo o procedimento abaixo:

$\checkmark$ Foi solicitado à paciente para que se sentasse em uma cadeira, mantendo os pés apoiados no chão e as mãos apoiadas no colo. Os tender points foram demarcados com lápis dermatográfico e avaliados na seguinte ordem: occipital, cervical baixa anterior, trapézio, supraespinhoso, segunda articulação costocondral, epicôndilo lateral e borda medial do joelho, bilateralmente.

$\checkmark$ Foi solicitado que a paciente permanecesse em posição ortostática e foram demarcados com lápis dermatográfico e avaliados os tender points de glúteo e trocânter maior bilateralmente.

$\checkmark \mathrm{Na}$ avaliação do limiar de dor dos tender points, foi aplicada uma pressão perpendicular à superfície da pele, sendo aumentada gradativamente a cada $0,1 \mathrm{Kg}$ até o momento em que a paciente referisse dor.

Neste trabalho consideraram-se resultados positivos aqueles abaixo de 2,6 $\mathrm{kg} / \mathrm{cm}^{2}$, limite que equivale ao de $4,0 \mathrm{~kg} / \mathrm{cm}^{2}$, descrito nos estudos de Wolfe et al ${ }^{1}$. Quando estes definiram o limite de $4,0 \mathrm{~kg} / \mathrm{cm}^{2}$, usavam utilizado um dolorímetro com ponta de 1,54 cm de diâmetro. O utilizado neste estudo tem apenas $1,0 \mathrm{~cm}$; por uma simples regra de três, chega-se ao valor de $2,6 \mathrm{~kg} / \mathrm{cm}^{2} \quad 59$.

Teste de flexibilidade. A avaliação da flexibilidade foi realizada através da medida da distância (centímetros) entre o terceiro dedo e o solo. Neste teste, o indivíduo foi colocado em posição ortostática com os pés unidos, ou em caso de valgismo com os joelhos unidos, e foi pedido que realizasse a flexão máxima de tronco objetivando alcançar o chão, com os membros superiores pendendo à frente 
do mesmo, não sendo permitida a flexão das pernas. Foi medida a distância, em centímetros, da ponta do terceiro dedo da mão direita até o solo com uma fita métrica. Foi considerado alongamento ideal quando o indivíduo tocava a mão no solo. Caso o indivíduo alcançasse facilmente o solo, o mesmo era posicionado sobre um degrau de madeira e novamente era medida a distância, em valores regativos, entre o terceiro dedo e o solo ${ }^{53}$.

Devido à dificuldade de leitura de algumas pacientes (semialfabetizadas ou analfabetas), foi realizada leitura conjunta dos questionários FIQ, SF-36 e McGill.

Fibromyalgia Impact Questionnaire (FIQ) ${ }^{54}$. O FIQ é um instrumento de avaliação de qualidade de vida, específico para fibromialgia. Este questionário envolve questões relacionadas à capacidade funcional, situação profissional, distúrbios psicológicos e sintomas. Quanto maior o escore, maior é o impacto da fibromialgia na qualidade de vida (Anexo 3).

Medical Outcomes study 36-item Short-Form Health Survey (SF-36) ${ }^{55}$. Foi utilizada a forma traduzida para o Português e validada por Ciconelli ${ }^{60}$. O SF-36 é um instrumento genérico de avaliação de qualidade de vida. Este questionário consiste de 36 itens, englobados em oito componentes: capacidade funcional (10 itens), aspectos físicos (4 itens), dor (2 itens), estado geral de saúde (5 itens), vitalidade (4 itens), aspectos sociais ( 2 itens), aspectos emocionais (3 itens), saúde mental (5 itens) e mais uma questão de avaliação comparativa entre as condições de saúde atual e a de um ano atrás. Cada componente varia de zero a cem, sendo zero o pior escore e cem o melhor escore (o questionário SF-36 e o cálculo dos escores estão representados no Anexo 4). 
The McGill Pain Questionnaire. Foi utilizada a forma adaptada para o Português por Pimenta ${ }^{56}$. O questionário é organizado em classes: sensorial, afetiva, avaliativa e mista, e em subclasses descrevendo a qualidade da dor. Devem ser escolhidas as palavras que melhor descreverem sua dor. Pede-se para a paciente escolher uma palavra de cada subcategoria, permitindo ao sujeito a opção de não escolher nenhuma. A análise é feita por categorias; através da soma dos valores associados às palavras selecionadas (Anexo 5).

Todos os sujeitos dos dois grupos assinaram o Termo de Consentimento Livre e Esclarecido (Anexo 6) e participaram da sessão educativa logo após a avaliação fisioterapêutica, com objetivo de poderem iniciar o tratamento em igualdade de conhecimento a respeito da fibromialgia.

A sessão educativa foi individual e realizada após a avaliação inicial. Nesta sessão, os sujeitos foram informados sobre a natureza da fibromialgia, os sintomas, o tratamento (enfatizando a importância dos exercícios) e as conseqüências sobre as atividades de vida diária. Foram ensinadas algumas estratégias de ergonomia, como carregamento de peso extracorporal e posturas adequadas para realização das atividades de vida diária e prática (trabalho). Por último, foi ensinado um programa básico de exercícios, composto por 11 exercícios para alongamento dos músculos: glúteos, paravertebrais, isquiotibiais, peitorais, escalenos, intercostais e trapézio. As pacientes receberam uma cartilha (Anexo 6) com todas as informações sobre a fibromialgia com ilustrações e descrições dos exercícios ensinados. A cartilha foi fornecida a todas as pacientes do estudo para aumentar a adesão à realização dos exercícios no domicílio. Foram orientadas para ignorarem os exercícios contidos nas páginas 22 e 24, uma vez que havia muita dificuldade na realização destes. 


\section{B) Intervenção}

\section{Grupo exercícios aeróbicos, alongamento e orientação (G1)}

Os sujeitos designados para o grupo exercícios aeróbicos, alongamento e orientação (G1) foram avaliados e realizaram a sessão educativa. Em seguida, as pacientes iniciaram o tratamento fisioterapêutico de 16 sessões ( 8 semanas), sendo atendidas em dupla, duas vezes por semana, com duração de uma hora e meia.

O programa terapêutico seguiu o protocolo:

$\checkmark$ Inicialmente, foi realizado exercício aeróbico em bicicleta ergométrica sem carga por 30 minutos. A PA, FC e a sensação de desconforto das pacientes foram aferidas antes, durante (15 minutos após início da atividade) e ao término do exercício durante as primeiras três sessões. Nas demais sessões, as variáveis, PA e FC, foram aferidas somente no início e término da atividade.

$\checkmark$ Em seguida, foram realizados todos os exercícios de alongamento muscular propostos na cartilha, exceto os exercícios das páginas 22 e 24 . Os exercícios de alongamento muscular correspondem aos músculos específicos de cada cadeia, a saber:

Cadeia respiratória: músculos escalenos, peitoral menor, intercostais e diafragma;

Cadeia posterior: músculos paravertebrais, isquiotibiais, glúteos e tríceps da perna;

Cadeia ântero-interna da bacia: músculos iliopsoas, adutores e rotadores mediais do quadril; 
Cadeia anterior do braço: músculos trapézio, deltóide, flexores de cotovelo, punho e dedos;

Cadeia ântero-interna do ombro: músculos subescapular, peitoral maior e coracobraquial.

Nas três primeiras sessões, cada exercício foi repetido cinco vezes e a posição mantida por 30 segundos. Após a terceira sessão, cada exercício foi repetido dez vezes e a posição mantida por 30 segundos.

Todos as pacientes receberam ilustração e descrição destes exercícios (Anexo 7) para realização dos mesmos em casa, nos demais dias em que não era realizada a fisioterapia no hospital.

\section{Grupo TENS, alongamento, exercícios aeróbicos e orientação (G2)}

Os sujeitos designados para o grupo TENS, alongamento, exercícios aeróbicos e orientação(G2) foram avaliados e realizaram a sessão educativa idêntica ao G1. Em seguida, iniciaram o tratamento fisioterapêutico de 16 sessões, sendo atendidas em dupla, duas vezes por semana, com duração de uma hora e meia, descrito a seguir:

$\checkmark$ A terapia por exercícios foi idêntica ao protocolo de G1.

$\checkmark$ Em seguida, foi realizado tratamento com a corrente TENS. Os eletrodos foram colocados nos pontos do trapézio e supraespinhal bilateralmente (pontos 5, 6, 7 e 9 do Quadro 1) e seguiram os seguintes parâmetros: o modo contínuo, o pulso $(\mathrm{P})$ de $150 \mathrm{~Hz}$, a freqüência $(\mathrm{F})=150 \mathrm{~ms}$, a intensidade (i) foi aumentada vagarosamente até o limite álgico suportável pela paciente (não atingiu ponto de fasciculação muscular); esses 
parâmetros foram mantidos por 10 minutos e a intensidade (i) foi aumentada após 10 e 20 minutos.

\section{C) Análise estatística}

Para a comparação intragrupo, foi usado o teste t-Student, unicaudal e pareado. Para comparar os grupos foi feito um teste de homogeneidade baseado na estatística Qui-quadrado de Pearson, com correção de Yates quando necessário. Para o estudo de associação entre os resultados dos dois grupos utilizou-se um teste de independência baseado na estatística Qui-quadrado de Pearson com correção de Yates quando necessário.

Para uma melhor comparação e possíveis composições, realizourse a normalização dos resultados obtidos do questionário FIQ. O objetivo foi que todos os índices variassem dentro dos mesmos limites, no caso entre 0 e 10. Para o cálculo do FIQ dividiu-se a variável Capacidade Funcional por 3 para que seu máximo fosse 10 como nas outras variáveis do FIQ. A medida final do FIQ é obtida pela média dos valores obtidos pelas oito variáveis relevantes. O índice assim obtido, FIQ total, é um número no intervalo de 0 a 10.

A partir do índice acima descrito é esperado que altos valores indiquem qualidade de vida prejudicada enquanto baixos valores indiquem boa qualidade de vida.

Toda a análise estatística foi realizada com nível de significância de 0,05. 


\section{RESULTADOS}

\section{Características da amostra}

A Tabela 1 mostra as características demográficas da amostra (idade, Índice de Massa Corpórea (IMC), estado civil, escolaridade e ocupação). Todos os participantes eram do sexo feminino com média de idade e desvio padrão de 51,85 $(9,04)$ para o do grupo G1 e 52,85 $(5,85)$ grupo G2. O IMC foi semelhante nos dois grupos. A escolaridade predominante foi primeiro grau incompleto $(67 \%)$ e a maioria tinha ocupação do lar (71\%). Foi realizado o teste de homogeneidade para os grupos G1 e G2 e não houve diferença estatística entre eles para idade e massa corpórea.

Tabela 1 - Características demográficas da amostra

\begin{tabular}{lll}
\hline Característica & $\begin{array}{l}\text { Grupo 1 } \\
(\mathbf{n = 1 4})\end{array}$ & $\begin{array}{l}\text { Grupo 2 } \\
(\mathbf{n}=\mathbf{1 4})\end{array}$ \\
\hline Idade (anos) & & \\
Média (DP) & $51,85(9,04)$ & $52,85(5,85)$ \\
IMC (Kg/cm $\left.)^{2}\right)$ & & \\
média (DP) & $28,57(3,90)$ & $28,52(3,56)$ \\
Estado civil & & \\
Casada & $7(50 \%)$ & $8(57,14 \%)$ \\
Solteira & $1(7,14 \%)$ & $1(7,14 \%)$ \\
Separada & $2(14,28 \%)$ & $1(7,14 \%)$ \\
Viúva & $4(28,577 \%)$ & $4(28,57 \%)$ \\
Escolaridade & & \\
Sem estudo & $3(21,42 \%)$ & $2(14,28 \%)$ \\
$1^{\circ}$ grau incompleto & $9(64,28 \%)$ & $10(71,42 \%)$ \\
$1^{\circ}$ grau completo & $2(14,28 \%)$ & $1(7,14 \%)$ \\
$2^{\circ}$ grau completo & 0 & $1(7,14 \%)$ \\
Ocupação & & \\
Do lar & $9(64,28 \%)$ & $11(78,57 \%)$ \\
Diarista & $3(21,42 \%)$ & $2(14,28 \%)$ \\
Outras & $2(14,28 \%)$ & $1(7,14 \%)$ \\
\hline
\end{tabular}


A Tabela 2 mostra as características clínicas da amostra relacionadas à anamnese (uso de medicamentos, história da dor) e ao exame físico (cadeias musculares comprometidas). Apenas $17,85 \%$ da amostra total não faz uso de medicação, sendo o antidepressivo $(39,28 \%)$ o medicamento mais utilizado. A média do tempo de dor foi semelhante nos dois grupos e as cadeias musculares posterior e de membros superiores apresentaram-se encurtadas em 100\% da amostra.

Tabela 2 - Características clínicas da amostra

\begin{tabular}{lll}
\hline Característica & $\begin{array}{l}\text { Grupo G1 } \\
(\mathbf{n = 1 4})\end{array}$ & $\begin{array}{l}\text { Grupo G2 } \\
(\mathbf{n = 1 4 )}\end{array}$ \\
\hline Medicamentos para dor & & \\
Nenhum & $3(21,42 \%)$ & $2(14,28 \%)$ \\
Antidepressivo & $6(42,85 \%)$ & $5(35,71 \%)$ \\
Antiinfla matório & $1(7,14 \%)$ & $2(14,28 \%)$ \\
Analgésico & $2(14,28 \%)$ & $4(28,57 \%)$ \\
Outros & $2(14,28 \%)$ & $1(7,14) \%$ \\
Fator de piora da dor & & \\
Esforço físico & $4(28,57 \%)$ & $9(64,28 \%)$ \\
Nervosismo & $2(14,28 \%)$ & $1(7,14 \%)$ \\
Dificuldade para dormir & $4(28,57 \%)$ & $1(7,14 \%)$ \\
Outros motivos & $4(28,57 \%)$ & $3(21,42 \%)$ \\
Tempo de dor (anos) & & \\
Média/DP & & \\
= a cinco anos & $7,82 \pm 5,85$ & $7,64 \pm 3,38$ \\
$>$ que cinco anos & $6(42,85 \%)$ & $5(35,71 \%)$ \\
Cadeias musculares (encurtamento) & $8(57,14 \%)$ & $9(64,28 \%)$ \\
Posterior & & \\
Respiratória & $14(100 \%)$ & $14(100 \%)$ \\
Anterior do braço & $10(71,42 \%)$ & $12(85,71 \%)$ \\
Antero-interna do ombro & $14(100 \%)$ & $14(100 \%)$ \\
Antero-interna da bacia & $14(100 \%)$ & $14(100 \%)$ \\
\hline & $9(64,28 \%)$ & $10(71,42 \%)$ \\
\hline
\end{tabular}




\section{Comparação dos dados iniciais e finais de cada grupo}

A Tabela 3 mostra os escores da flexibilidade mensurada através do índice terceiro dedo-solo antes e após o tratamento. Houve diferença estatisticamente significante $\mathrm{G} 1(\mathrm{p}=0,000)$ e $\mathrm{G} 2(\mathrm{p}=0,046)$. É importante salientar que, quanto mais próximo de zero ou negativo for o valor do índice terceiro dedo-solo, melhor será a flexibilidade.

TABELA 3 - Média, desvio padrão (DP) e valor de p do índice terceiro dedo-solo

\begin{tabular}{lcccccc}
\hline & \multicolumn{3}{c}{ Grupo 1 $(\mathbf{n}=\mathbf{1 4})$} & \multicolumn{3}{c}{ Grupo 2 (n= 14) } \\
\cline { 2 - 7 } & $\begin{array}{c}\text { Inicial } \\
\text { média (DP) }\end{array}$ & $\begin{array}{c}\text { Final } \\
\text { média (DP) }\end{array}$ & $\mathbf{p}$ & $\begin{array}{c}\text { Inicial } \\
\text { média (DP) }\end{array}$ & $\begin{array}{c}\text { Final } \\
\text { média (DP) }\end{array}$ & $\mathbf{p}$ \\
& & & & & & \\
\hline $\begin{array}{l}\text { Índice 30. } \\
\text { dedo }- \text { solo }(\mathrm{cm})\end{array}$ & $11,57(8,39)$ & $5,82(8,60)$ & $\mathbf{0 , 0 0 0}$ & $14,96(10,32)$ & $12,60(7,92)$ & $\mathbf{0 , 0 4 6}$ \\
\hline
\end{tabular}

A corrente TENS nos quatro tender points foi aplicada somente no Grupo 2. A Tabela 4 mostra a média e o desvio padrão do limiar de dor destes e, a média do limiar de dor dos 18 tender points. É importante salientar que quanto maior o limiar de dor menor a sensibilidade dolorosa, e neste trabalho utilizamos o limite $=2,6 \mathrm{Kgf}$ para nomear um tender point como positivo. Após a aplicação do TENS, houve aumento do limiar de dor dos quatro pontos estudados, porém somente o trapézio esquerdo e supraespinhoso direito apresentaram diferença estatisticamente significante ( $\mathrm{p}=0,009$ e 0,041 ), sendo que o primeiro obteve melhora do limiar e o segundo, piora. Já no limiar de dor dos 18 tender, o grupo G1 apresentou diferença estatisticamente significante $(\mathrm{p}=0,005)$, porém com diminuição do limiar de dor, ou 
seja, houve piora da sensibilidade dolorosa e o grupo G2 não apresentou diferença estatisticamente significante $(\mathrm{p}=0,320)$.

TABELA 4 - Média, desvio padrão e valor de “ $p$ ” para o limiar de dor nos 4 tender points tratados com TENS no grupo G2 e a dolorimetria dos 18 tender points (TP)

\begin{tabular}{lllllll}
\hline & \multicolumn{3}{c}{ Grupo 1 (n= 14) } & & \multicolumn{3}{c}{ Grupo 2 (n= 14) } \\
\cline { 2 - 7 } Limiar de dor & Inicial & Final & $\mathbf{p}$ & Inicial & Final & p \\
& média (DP) & média (DP) & & média (DP) & média (DP) & \\
\hline Trapézio D & $2,57(0,68)$ & $2,36(1,15)$ & 0,249 & $2,60(0,45)$ & $2,82(0,89)$ & 0,211 \\
Trapézio E & $2,57(0,56)$ & $2,46(1,10)$ & 0,327 & $2,60(0,42)$ & $3,01(0,65)$ & $\mathbf{0 , 0 0 9}$ \\
Supraespinhoso D & $2,60(0,68)$ & $2,30(1,02)$ & 0,124 & $3,01(0,65)$ & $2,95(1,03)$ & $\mathbf{0 , 0 4 1}$ \\
Supraespinhoso E & $2,60(0,64)$ & $2,33(1,24)$ & 0,180 & $2,85(0,36)$ & $3,04(0,69)$ & 0,087 \\
\hline Dolorimetria & $2,37(0,40)$ & $2,10(0,55)$ & $\mathbf{0 , 0 0 5}$ & $2,48(0,38)$ & $2,54(0,67)$ & 0,320 \\
dos 18 TP & & & & & &
\end{tabular}

A Tabela 5 mostra os valores da avaliação da dor pela VAS e Questionário de dor da McGill. Na avaliação da VAS, nota-se que somente o grupo G2 apresentou diminuição significante da dor ( $\mathrm{p}=0,005)$. No Questionário de dor da McGill, o grupo G1 apresentou diminuição significante da dor observado através do escore total $(\mathrm{p}=0,030)$ e das categorias sensorial $(\mathrm{p}=0,024)$ e afetiva $(\mathrm{p}=0,050)$. No Grupo $\mathrm{G} 2$, também houve diminuição significante no escore total $(p=0,017)$ e nas categorias sensorial $(\mathrm{p}=0,011)$ e avaliativa $(\mathrm{p}=0,019)$. Em relação aos descritores deste questionário, os mais selecionados foram: no Grupo G1, "cansativa" (86,67\%) (categoria afetiva) seguido por "fina" (73,33\%), "agulhada" $(66,67 \%)$ e "pontada" $(66,67 \%)$ (categoria sensorial). No Grupo G2, os mais frequientes foram: "cansativa" e "enjoada", ambos com 53,33\% (categoria afetiva), seguidos por "formigamento" com 53,33\%, "agulhada" e "fina", ambos com 46,66\% (categoria sensorial). 
TABELA 5 - Média, desvio padrão e valor de “p” para a VAS e Questionário McGill de dor.

\begin{tabular}{lcccccc}
\hline & \multicolumn{3}{c}{ Grupo 1 (n= 14) } & \multicolumn{3}{c}{ Grupo 2 (n = 14) } \\
& $\begin{array}{l}\text { Inicial } \\
\text { média }(\mathrm{DP})\end{array}$ & $\begin{array}{c}\text { Final } \\
\text { média (DP) }\end{array}$ & $\mathbf{p}$ & $\begin{array}{c}\text { Inicial } \\
\text { média (DP) }\end{array}$ & $\begin{array}{c}\text { Final } \\
\text { média (DP) }\end{array}$ & $\mathbf{p}$ \\
\hline VAS & $7,77(1,91)$ & $6,82(2,84)$ & 0,167 & $7,66(1,59)$ & $5,35(2,18)$ & $\mathbf{0 , 0 0 5}$ \\
Sensorial & $17,84(4,33)$ & $15,92(5,70)$ & $\mathbf{0 , 0 2 4}$ & $17,14(4,60)$ & $13,92(7,10)$ & $\mathbf{0 , 0 1 1}$ \\
Afetiva & $6,61(3,01)$ & $5,78(2,15)$ & $\mathbf{0 , 0 5 0}$ & $5,78(2,15)$ & $4,71(2,39)$ & 0,105 \\
Avaliativa & $2,70(1,87)$ & $2,62(2,05)$ & 0,430 & $2,85(1,65)$ & $1,85(1,40)$ & $\mathbf{0 , 0 1 9}$ \\
Miscelânea & $6,38(4,01)$ & $5,61(1,80)$ & 0,185 & $5,21(1,80)$ & $5,00(2,28)$ & 0,427 \\
McGill (total) & $33,35(10,04)$ & $30,07(10,26)$ & $\mathbf{0 , 0 3 0}$ & $31,71(8,29)$ & $26,64(13,20)$ & $\mathbf{0 , 0 1 7}$ \\
\hline
\end{tabular}

A Tabela 6 mostra os resultados do Questionário de Impacto da Fibromialgia (FIQ) antes e após o tratamento. Observa-se que o Grupo G1 obteve melhora estatisticamente significante nas questões sono e depressão $(p=0,020$ e 0,029$)$ e, no Grupo G2, no FIQ total $(\mathrm{p}=0,003)$ e nas categorias: capacidade de trabalho $(\mathrm{p}=0,003)$, dor $(\mathrm{p}=0,000)$, cansaço $(\mathrm{p}=0,010)$, rigidez $(\mathrm{p}=0,058)$ e depressão $(\mathrm{p}=0,053)$. 
Tabela 6 - Média, desvio padrão e valor de “ $p$ ” para o Questionário FIQ.

\begin{tabular}{lcccccc}
\hline & \multicolumn{2}{c}{ Grupo 1 $(\mathbf{n}=\mathbf{1 4})$} & \multicolumn{3}{c}{ Grupo 2 (n= 14) } \\
FIQ & $\begin{array}{l}\text { Inicial } \\
\text { média (DP) }\end{array}$ & $\begin{array}{c}\text { Final } \\
\text { média (DP) }\end{array}$ & $\mathbf{p}$ & $\begin{array}{c}\text { Inicial } \\
\text { média (DP) }\end{array}$ & $\begin{array}{c}\text { Final } \\
\text { média (DP) }\end{array}$ & $\mathbf{p}$ \\
\hline C.Funcional & $12,92(6,00)$ & $13,46(6,21)$ & 0,319 & $14,35(5,09)$ & $13,14(4,94)$ & 0,083 \\
C.Trabalho & $7,12(3,23)$ & $6,42(3,38)$ & 0,151 & $7,86(2,07)$ & $6,15(2,38)$ & $\mathbf{0 , 0 0 3}$ \\
Dor & $7,57(2,72)$ & $6,02(3,57)$ & 0,070 & $8,30(1,64)$ & $6,15(2,55)$ & $\mathbf{0 , 0 0 0}$ \\
Cansaço & $7,65(2,78)$ & $7,32(2,76)$ & 0,328 & $8,68(1,63)$ & $7,05(2,45)$ & $\mathbf{0 , 0 1 0}$ \\
Sono & $7,00(2,79)$ & $5,38(3,61)$ & $\mathbf{0 , 0 2 0}$ & $7,70(2,83)$ & $6,87(3,36)$ & 0,119 \\
Rigidez & $7,83(2,80)$ & $7,25(3,53)$ & 0,279 & $9,00(0,84)$ & $7,69(2,71)$ & $\mathbf{0 , 0 5 8}$ \\
Ansiedade & $9,19(0,84)$ & $8,52(2,46)$ & 0,117 & $8,40(1,58)$ & $7,18(3,13)$ & 0,078 \\
Depressão & $8,16(1,97)$ & $6,61(3,43)$ & $\mathbf{0 , 0 2 9}$ & $7,45(2,22)$ & $6,13(3,37)$ & $\mathbf{0 , 0 5 3}$ \\
Total & $6,10(1,62)$ & $5,69(1,80)$ & 0,098 & $6,35(1,06)$ & $5,41(1,54)$ & $\mathbf{0 , 0 0 3}$ \\
\hline
\end{tabular}

A Tabela 7 mostra os dados da qualidade de vida avaliada pelo SF-36. É importante lembrar que o Questionário SF-36 varia de 0 a 100 e quanto maior o escore, melhor a qualidade de vida. Observa-se que no grupo G1 houve melhora estatisticamente significante nas categorias: aspectos sociais $(p=0,047)$ e saúde mental $(p=0,041)$ e no SF-36 total $(p=0,027)$, no grupo $G 2$, dor $(p=0,039)$, estado geral de saúde $(\mathrm{p}=0,034)$ e saúde mental $(\mathrm{p}=0,039)$. 
Tabela 7 - Média, desvio padrão e valor de “p” para o Questionário de Qualidade de Vida SF-36

\begin{tabular}{lcccccc}
\hline & \multicolumn{2}{c}{ Grupo 1 (n= 14) } & \multicolumn{3}{c}{ Grupo 2 (n= 14) } \\
SF-36 & $\begin{array}{l}\text { Inicial } \\
\text { média (DP) }\end{array}$ & $\begin{array}{c}\text { Final } \\
\text { média (DP) }\end{array}$ & $\mathbf{p}$ & $\begin{array}{c}\text { Inicial } \\
\text { média (DP) }\end{array}$ & $\begin{array}{c}\text { Final } \\
\text { média (DP) }\end{array}$ & p \\
\hline C.Funcional & $43,46(17,24)$ & $49,23(13,36)$ & 0,114 & $35,35(14,47)$ & $42,85(20,25)$ & 0,177 \\
Aspecto Físico & $25,00(36,79)$ & $36,53(39,01)$ & 0,152 & $7,14(18,15)$ & $19,64(36,92)$ & 0,227 \\
Dor & $35,76(15,07)$ & $38,76(19,14)$ & 0,250 & $25,21(17,80)$ & $38,00(23,00)$ & $\mathbf{0 , 0 3 9}$ \\
E.Geral Saúde & $39,30(19,79)$ & $35,00(20,59)$ & 0,137 & $24,42(16,66)$ & $33,85(20,11)$ & $\mathbf{0 , 0 3 4}$ \\
Vitalidade & $34,23(20,29)$ & $37,69(19,74)$ & 0,199 & $35,71(17,41)$ & $38,21(19,17)$ & 0,221 \\
A. Sociais & $47,11(27,07)$ & $64,42(23,85)$ & $\mathbf{0 , 0 4 7}$ & $47,32(26,48)$ & $46,42(24,72)$ & 0,350 \\
A. Emocionais & $23,07(34,38)$ & $38,46(38,11)$ & 0,152 & $21,42(33,60)$ & $14,28(28,38)$ & 0,255 \\
Saúde Mental & $33,71(19,45)$ & $42,00(25,23)$ & $\mathbf{0 , 0 4 1}$ & $35,14(17,48)$ & $46,00(15,59)$ & $\mathbf{0 , 0 3 9}$ \\
Total & $33,41(17,91)$ & $40,50(18,39)$ & $\mathbf{0 , 0 2 7}$ & $31,21(11,73)$ & $36,15(18,30)$ & 0,153 \\
\hline
\end{tabular}




\section{Comparação entre os grupos}

É importante salientar que a corrente TENS foi aplicada penas nos quatro tender points de supraespinhoso e trapézio direito e esquerdo do Grupo 2. A Figura 6 mostra a dispersão dos dados do limiar de dor nos tender points do supraespinhoso direito e esquerdo. Os pontos cujos valores estão abaixo da diagonal significam piora do limiar de dor e os acima, melhora, no final do tratamento para cada sujeito. Podese notar a tendência ao aumento do limiar de dor no grupo G2, entretanto, não confirmada no teste qui-quadrado (respectivamente no supraespinhoso direito e esquerdo, $\mathrm{p}=0,439$ e 0,251$)$.

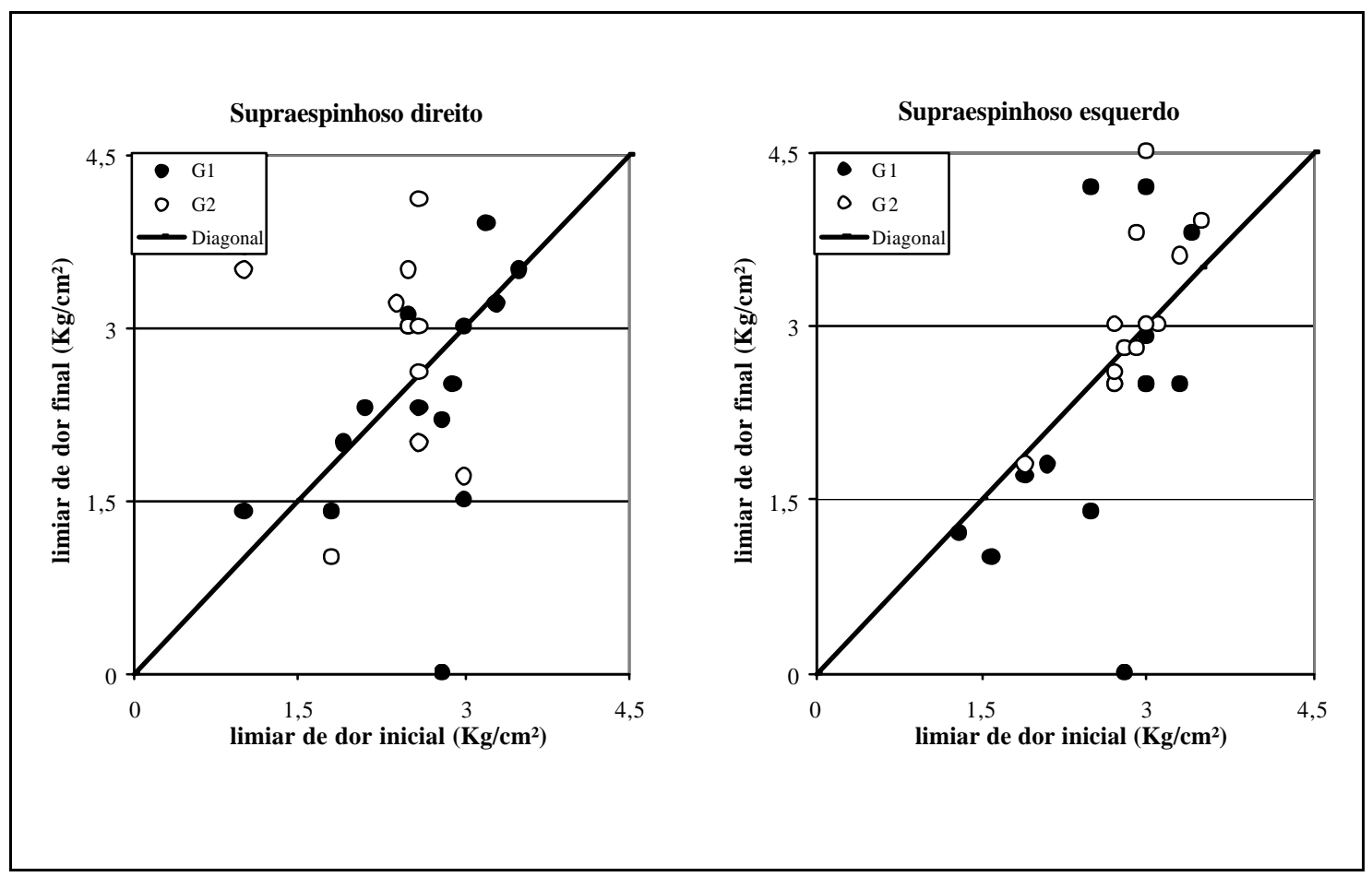

Figura 6 - Gráficos de dispersão dos dados do limiar de dor nos tender points supraespinhoso direito $(\mathrm{p}=0,439)$ e esquerdo $(\mathrm{p}=0,251)$

(Os sujeitos que estão acima da linha diagonal tiveram aumento do limiar de dor, ou seja, melhora). 
A Figura 7 mostra a dispersão dos dados do limiar de dor nos tender points trapézio direito e esquerdo. Os dados sugerem tendência ao aumento do limiar de sensibilidade dolorosa no grupo G2, sendo significante no teste qui-quadrado para o trapézio $\mathrm{E}(\mathbf{p}=\mathbf{0 , 0 1 5})$, porém não foi estatisticamente significante para trapézio $\mathrm{D}$ $(\mathrm{p}=0,439)$.

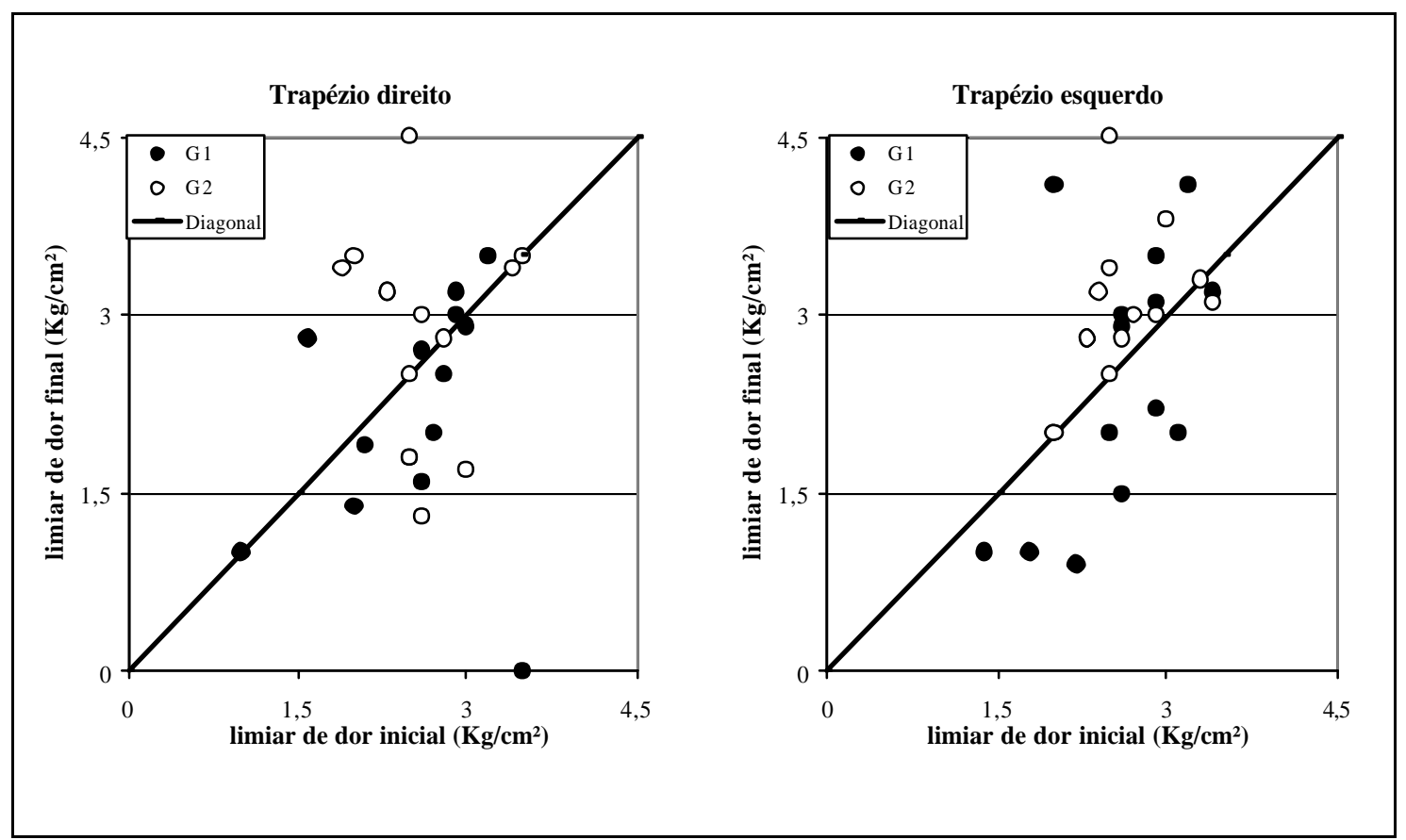

Figura 7 - Gráficos de dispersão do limiar de dor nos tender points de trapézio direito e esquerdo.

(Os sujeitos que estão acima da linha diagonal tiveram aumento do limiar de dor, ou seja, melhora). 
A Figura 8 mostra a dispersão dos dados da dolorimetria dos 18 tender points. Estes dados também sugerem tendência ao aumento do limiar de sensibilidade dolorosa no grupo $\mathrm{G} 2$, porém sem diferença estatisticamente significante $(p=0,121)$.

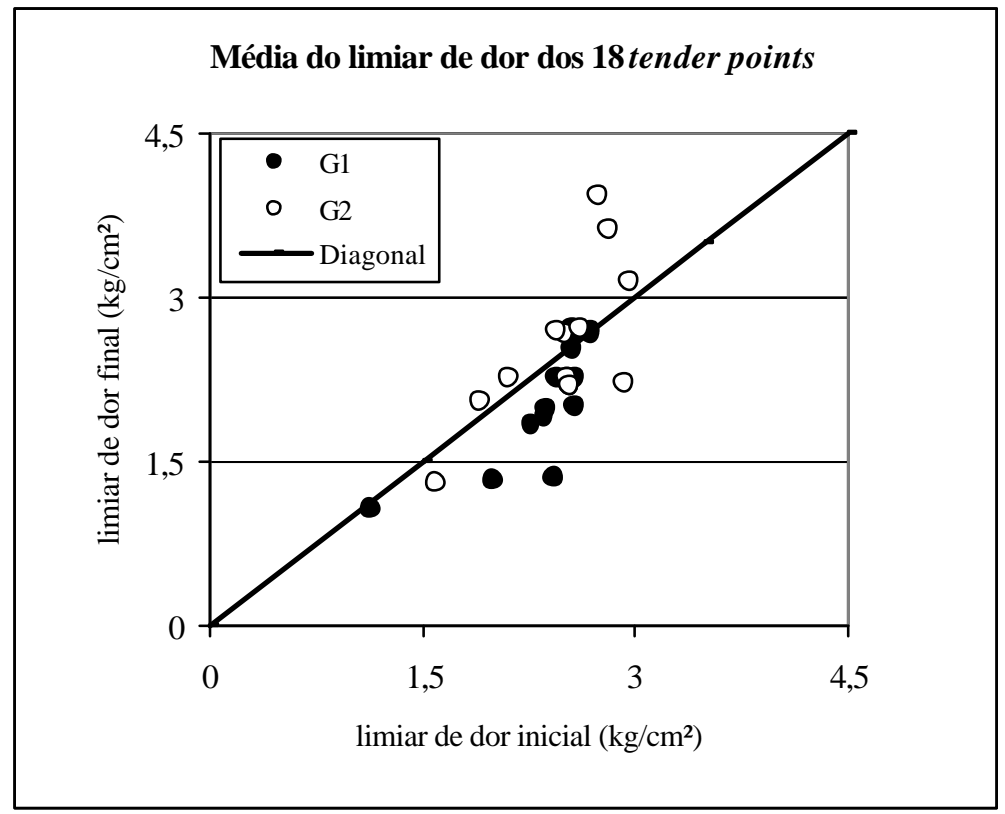

Figura 8 - Gráfico de dispersão da média do limiar de dor dos 18 tender points.

(Os sujeitos que estão acima da linha diagonal tiveram aumento do limiar de dor, ou seja, melhora).

Na Figura 9, observa-se a dispersão dos dados do questionário de qualidade de vida FIQ nas questões que utilizam a escala analógica visual (questões 4 a 10). Não houve diferença estatisticamente significante entre os grupos $(\mathrm{p}=0,418)$. 


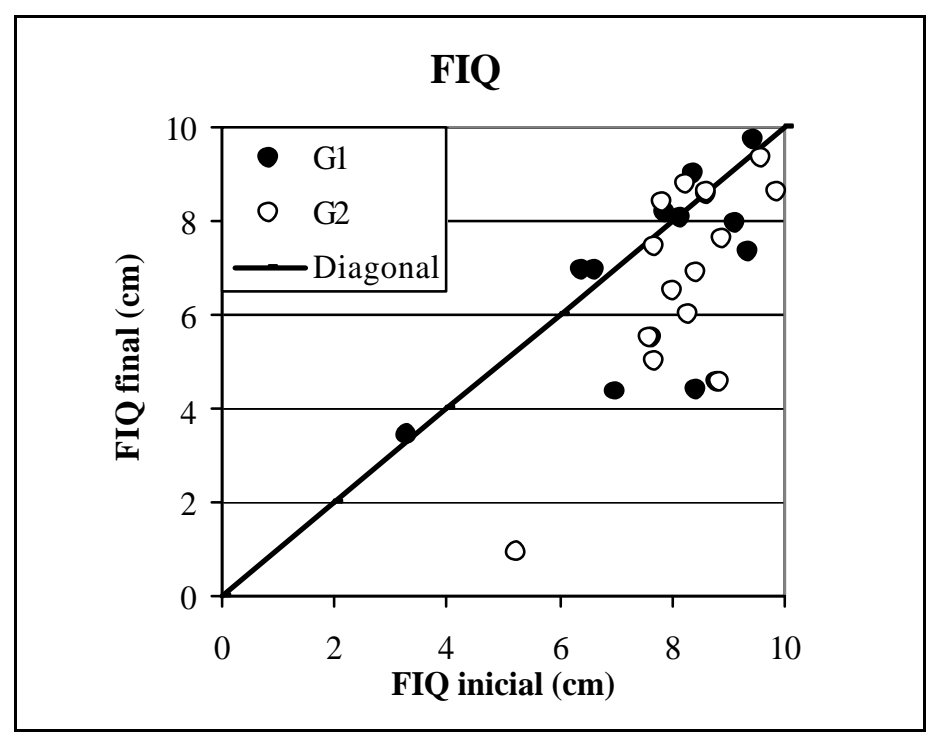

Figura 9 - Gráfico de dispersão dos dados do FIQ.

(Os sujeitos que estão abaixo da linha diagonal tiveram melhora da qualidade de vida).

A Figura 10 mostra a dispersão dos dados do Questionário de qualidade de vida SF-36. Nota-se que há uma tendência à melhora da qualidade de vida para ambos os grupos, porém o teste qui-quadrado não mostra diferença estatística $(\mathrm{p}=0,209)$. 


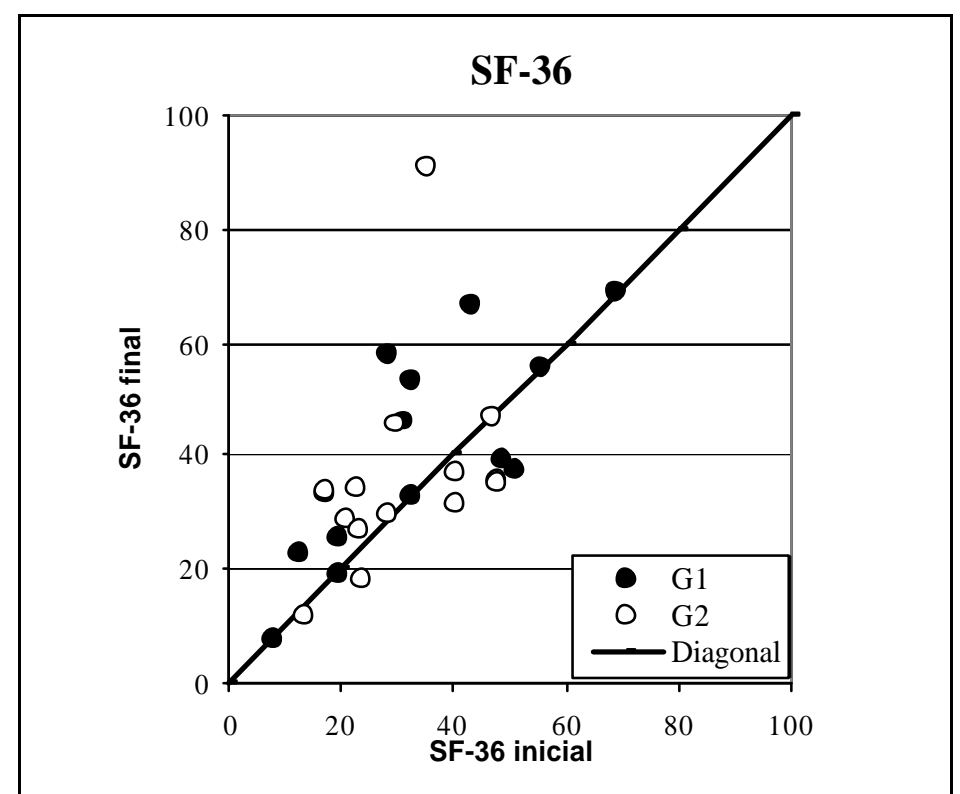

Figura 10 - Gráfico de dispersão dos dados do questionário SF-36.

(Os sujeitos que estão acima da linha diagonal tiveram melhora da qualidade de vida).

A Figura 11 mostra a dispersão dos dados do questionário de dor McGill. Pode-se observar uma tendência à diminuição do escore total em ambos os grupos, ou seja, melhora da percepção da dor, porém para o teste qui-quadrado $(\mathrm{p}=0,463)$ os grupos não apresentam diferença estatisticamente significante. 


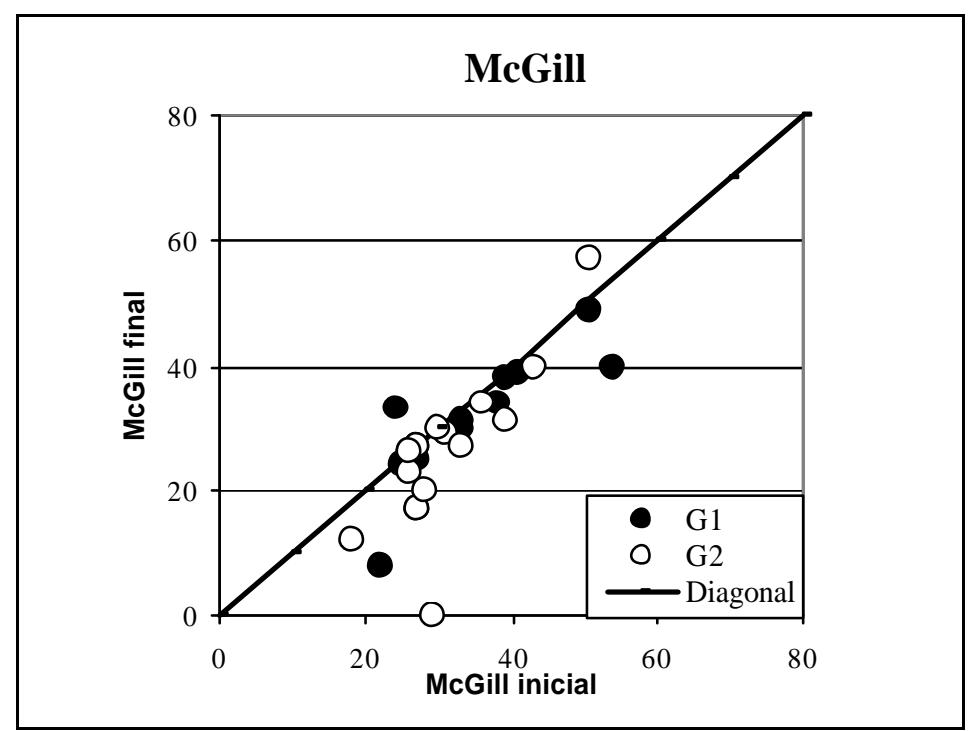

Figura 11 - Gráfico de dispersão dos dados do questionário McGill.

(Os sujeitos que estão abaixo da linha diagonal tiveram melhora da dor).

A Figura 12 mostra a dispersão dos dados da avaliação da dor pela VAS. Notase tendência à diminuição dos valores nos grupos G1 e G2, ou seja, melhora da percepção da dor, sem diferença estatisticamente significante $(\mathrm{p}=1,00)$.

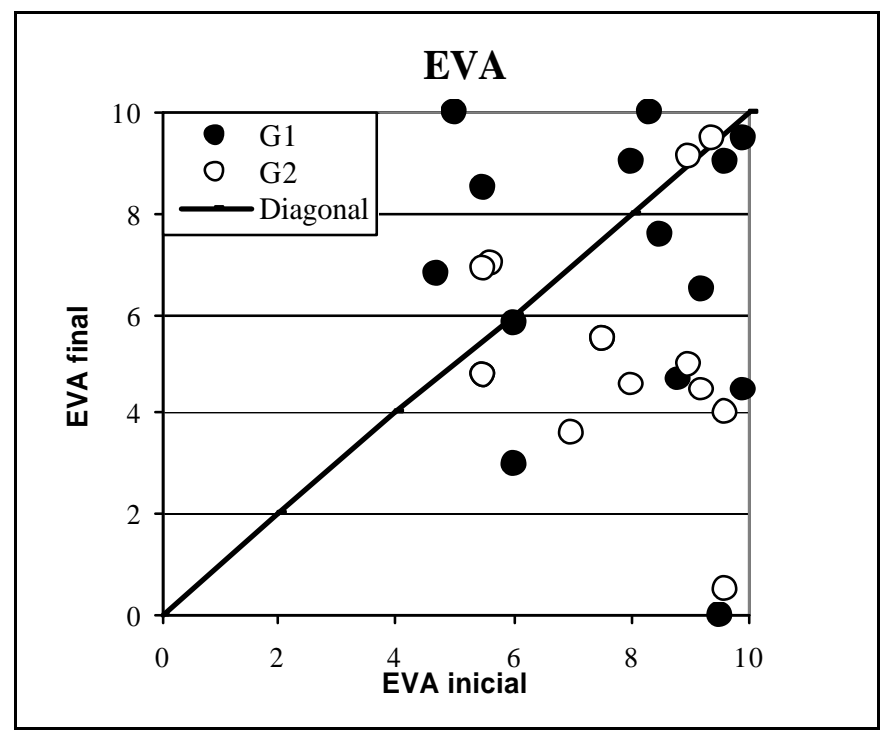

Figura 12 - Gráfico de dispersão dos dados da Escala Visual Analógica.

(Os sujeitos que estão abaixo da linha diagonal tiveram melhora da dor). 


\section{DiscuSsão}

Os dados de literatura mostram que as pacientes com fibromialgia têm limiar de dor mais baixo nos tender points ${ }^{60}$, assim aumentar o limiar de dor pode trazer alívio da sintomatologia e melhora da qualidade de vida. Vários estudos ${ }^{19,}$ 20, 21, 22 apontam para o benefício dos exercícios aeróbicos e de alongamento muscular na melhora da sintomatologia e qualidade de vida das pacientes com fibromialgia. A utilização de um meio físico complementar ao tratamento pode trazer benefício adicional para a melhora clínica dessas pacientes.

Esse estudo queria verificar a eficácia de um programa de tratamento fisioterapêutico composto de: tratamento com TENS em quatro tender points (trapézio e supraespinhoso, bilateralmente), exercícios de alongamento, exercícios aeróbicos e orientação educativa sobre a sintomatologia e a qualidade de vida de pacientes com fibromialgia.

Os dados deste estudo mostram que houve melhora da flexibilidade, dor e alguns aspectos da qualidade de vida nos dois grupos tratados. Entretanto, a terapia com exercícios e associação de TENS não apresentou diferença estatisticamente significante comparada ao grupo de pacientes tratados sem a associação desta.

A corrente TENS é um recurso amplamente utilizado ${ }^{34}$ para analgesia de dores crônicas e agudas e está acessível na maioria das clínicas de Fisioterapia. A revisão bibliográfica mostrou que há muita controvérsia com relação ao efeito após o tratamento com TENS. Alguns estudos mostraram que realmente houve alívio do sintoma dor nos sujeitos que receberam TENS $23,39,40,43,48,49,50,51,52$,outros estudos que utilizaram o TENS tiveram sucesso para potencializar o efeito de medicamentos 
44, 45, porém alguns estudos não mostraram diferença para o tratamento com TENS ${ }^{37}$, 41, 42, 46, 47 . A controvérsia existente na literatura torna difícil o estabelecimento de parâmetros adequados, assim como do tempo de utilização da TENS nos pacientes.

O estudo de Gashu et al. ${ }^{24}$ que utilizou TENS de baixa freqüência $(15 \mathrm{~Hz}) \mathrm{em}$ pacientes com síndrome fibromiálgica obteve melhora da dor. Deve-se lembrar que nesse estudo o limiar de dor nos tender points foi mensurado após cada sessão de TENS. O estudo de Bassan et al ${ }^{44}$ utilizou TENS no tratamento de fibromialgia em criança obtendo melhora da dor, porém houve associação com medicamento.

No presente trabalho utilizou-se a corrente TENS com alta freqüência $(150 \mathrm{~Hz})$ e isso pode ter contribuído para não se obter o resultado esperado, além disso, os outros parâmetros, como o tempo de aplicação (30 min), por exemplo, também podem ser fatores que interferiram no resultado. Nesse trabalho não foi mensurado o limiar de dor logo após o tratamento, pois optou-se por verificar se o efeito do TENS trazia benefício após um intervalo de tempo maior. Ao mensurar o limiar de dor logo após sua aplicação, talvez pudesse ser observada a diminuição do limiar de dor, porém a mensuração da sintomatologia e da qualidade de vida poderia sofrer interferência de um efeito efêmero de analgesia e alterar o resultado e por isso, não foi realizada a dolorimetria a cada sessão.

É importante lembrar que ao analisar a dor em pacientes com fibromialgia considerando a gravidade e o rigor de avaliação, alguns estudos concluíram que o questionário de dor da McGill e a escala visual analógica verificaram de maneira global o desconforto sentido pelos pacientes e a dolorimetria mostrou a sensibilidade em diversos pontos do corpo ${ }^{62,63}$. Ferreira et al ${ }^{64}$ e Marques et al ${ }^{61}$ mostraram que o 
Questionário McGill foi um instrumento eficaz e confiável para avaliar a qualidade e intensidade da dor.

Os dois grupos melhoraram a dor (mensuradas através da EVA e do McGill), porém não foi possível verificar diferença estatística entre eles. Assim provavelmente a melhora ocorreu devido aos exercícios aeróbicos e de alongamento muscular, o que está de acordo com a literatura pesquisada. Matsutani ${ }^{25}$ e Marques ${ }^{20}$ verificaram que os exercícios de alongamento muscular foram os principais responsáveis pela melhora da dor, sensibilidade dolorosa dos tender points e qualidade de vida em pacientes com Fibromialgia. Na literatura, vários estudos sugerem que exercícios de baixa intensidade sejam os mais efetivos no tratamento de pacientes com fibromialgia. Entre ele estão os exercícios aeróbicos (caminhada, exercícios aquáticos e bicicleta) e exercícios de alongamento muscular ${ }^{20,21}$.

Nesse estudo o tempo de tratamento proposto foi de oito semanas, pode ser que as pacientes com fibromialgia precisem de um tempo maior para se beneficiar dos exercícios físicos. Sabbag et al ${ }^{22}$ propuseram um programa de treinamento cardiovascular supervisionado (TCS) em mulheres com síndrome fibromiálgica utilizando esteira e observaram que a partir do $3^{\circ}$ mês de TCS, elas apresentaram maior tolerância à dor muscular e ao esforço, melhora da capacidade funcional cardiovascular e muscular periférica.

Durante o tratamento realizado nesse estudo foi solicitado que as pacientes não realizassem outros tratamentos para evitar fator de confusão. Foi permitido continuar com a terapia medicamentosa.

Os questionários de qualidade de vida mostraram que as mulheres deste estudo possuem qualidade de vida muito prejudicada. Apesar dos dois grupos terem obtido 
melhora em algumas categorias dos questionários, não foi possível verificar diferença estatística entre os grupos. O perfil sócio-econômico-cultural dessa amostra pode ter sido um fator que interferiu na análise dos resultados, por exemplo, $67 \%$ da amostra tinha o primeiro grau incompleto, fato que gera muita dificuldade na aplicação dos questionários, principalmente do SF-36. A grande maioria tinha dificuldades financeiras que interferia na alimentação da família (contavam com doação de cesta básica), por vezes as pacientes faltavam à terapia por falta de dinheiro para condução. Além disso, algumas pacientes moravam em regiões violentas e outras possuíam parentes reclusos em penitenciárias, fato que gerava tristeza constantemente relatada na terapia.

O tamanho da amostra também pode ter interferido no resultado final desse estudo. Pode ser que com uma amostra maior, revisão dos parâmetros da corrente TENS e maior período de tratamento, ${ }^{22}$ a associação entre os exercícios aeróbicos e de alongamento muscular com a TENS mostre contribuição positiva no alívio da sintomatologia e qualidade de vida das mulheres com fibromialgia.

Matsutani ${ }^{24}$ identificou que o profissional de saúde pode exercer influência no paciente, uma vez que este pode contribuir para melhora da qualidade vida destes. $\mathrm{O}$ fisioterapeuta solicita a realização dos exercícios (autocuidado), faz o acompanhamento da atividade (fornece atenção) e tenta promover parceria com o paciente através do conhecimento da sua condição e dos fatores de interferência (autoconhecimento) e isso torna o paciente elemento ativo no tratamento. Ao término do tratamento é possível observar a diferença entre as pacientes, pois agora possuem atitude mais ativa em relação à melhora de sua saúde, o que as tornam mais independentes e capazes. Outro fator que pode ter interferido no resultado da 
avaliação final das pacientes desse estudo é o fato das pacientes saberem que era o último contato com a fisioterapeuta. $\mathrm{O}$ acesso ao sistema de saúde é moroso e isso gera desconforto e preocupação para seus usuários. Pode ser que, permanecer em tratamento no hospital trouxesse sensação de seguridade às pacientes, uma vez que, se houvesse outro problema de saúde, estaria mais próxima do local de tratamento. Além disso, o vínculo formado entre fisioterapeuta e paciente envolve cuidado e segurança, e no momento da alta pode haver tristeza e desamparo. Esse fato pode ter contribuído de maneira negativa nas respostas dos questionários.

No início da avaliação final, as pacientes foram questionadas sobre o tratamento de maneira informal e, a maioria delas $(89,28 \%)$, referiu que conseguiu modificar suas atitudes em relação às suas atividades diárias, como por exemplo: incluir a prática de exercícios em sua rotina semanal, fragmentar as atividades domésticas para evitar sobrecarga em um único dia, identificar fatores facilitadores da dor, assim como fatores de alívio da dor, correção da postura nas atividades diárias, entre outros aprendizados. Agora, as pacientes possuem maior conhecimento sobre suas capacidades, seus limites e assim podem tentar atingir uma convivência harmoniosa e equilibrada com sua patologia. Também passaram a perceber melhor seu corpo e puderam observar a melhora gradativa no desempenho nos exercícios, o que foi comprovado pelo bom resultado no teste de flexibilidade em ambos os grupos. Um estudo de Mello ${ }^{65}$ sugere que técnicas de reeducação postural e identificação da imagem e esquema corporal devem ser utilizadas em pacientes com síndrome fibromiálgica para identificar e corrigir fatores determinantes do quadro álgico. 
Kendall et $\mathrm{al}^{66}$ relataram que uma boa biomecânica corporal é importante para o bem-estar, principalmente pela sobrecarga imposta ao corpo humano diariamente. Os exercícios de alongamento podem ser um bom meio para otimizar a biomecânica corporal além de auxiliar na consciência dos movimentos corporais ${ }^{24}$. A atividade física é fator de proteção contra doenças crônicas e eficaz na sua terapêutica. O sedentarismo causa limitações, reversíveis com atividade física ${ }^{67}$.

Os dados relativos à flexibilidade foram comunicados às pacientes no início e ao término do tratamento para que estas pudessem conhecer e acompanhar a melhora após os exercícios de alongamento. Esta medida teve caráter informativo e educativo, sendo estabelecido o objetivo de atingir o solo no teste de flexibilidade que visou estimular a adesão ao protocolo de exercícios domiciliares (cartilha). Deve-se lembrar que os programas de educação ao paciente têm sido desenvolvidos no tratamento de condições crônicas como complemento dos tratamentos convencionais $^{68}$. Segundo Keel ${ }^{69}$, uma intervenção terapêutica bem-sucedida a pacientes com dor crônica deve conter: mudança na atitude, autocontrole da dor e expectativas positivas. 


\section{Conclusão}

Ao observar a eficácia de um programa fisioterapêutico composto de: tratamento com TENS em quatro tender points (trapézio e supraespinhoso, bilateralmente), exercícios aeróbicos e de alongamento muscular e orientação educativa sobre a sintomatologia e qualidade de vida de pacientes com fibromialgia, observou-se que:

1. Os exercícios aeróbicos e de alongamento foram eficazes na melhora da dor e qualidade de vida das pacientes.

2. O tratamento com a corrente TENS como recurso complementar aos exercícios não mostrou diferença com relação à melhora da dor, sensibilidade dolorosa e qualidade de vida.

3. Os exercícios aeróbicos e de alongamento foram eficazes na melhora da flexibilidade das pacientes. 


\section{REFERÊNCIAS BIBLIOGRÁFICAS}

1. Wolfe F, Smythe HA, Yunus MB, Bennett RM, Bombardier C, Goldenberg DL. The American College of Rheumatology 1990. Criteria for the classification of fibromyalgia: Report of the Multicenter Criteria Commitee. Arthritis Rheum 1990; 33: $160-72$.

2. Okifuji A, Turk JD, Sinclair D, Starz TW, Marcus DA. A standardized manual tender point survey. I. Development and determination of a threshold point for identification of positive tender points in Fibromyalgia Syndrome. J Rheumatol 1997; 24: 377-83.

3. Haun MVA, Ferraz MB, Pollak DF. Validação dos critérios do Colégio Americano de Reumatologia (1990) para classificação da fibromialgia, em uma população brasileira. Rev Bras Reumatol 1999; 39: 221-30.

4. Martinez JE, Ferraz MB, Sato EI, Atra E. Fibromyalgia versus rheumatoid arthristis: a longitudinal comparison of the quality of life. J Rheumatol 1995; 22: 270-4

5. Wolfe TA, Bruusgaard D, Henriksson KG, Littlejohn G, Raspe H, Vaeroy H. Fibromyalgia and Disability. Scan J Rheumatol 1995; 24:112-8.

6. Riberto M, Battistella LR. Comorbidades em fibromialgia. Rev Bras Reumatol 2002; 42: 1-7.

7. Simms RW. Fibromyalgia is not a muscle disorder. Am J Med Sci 1998; 315: 34650 .

8. Park JH, Phothimat P, Oates CT, Hernanz-Schulman M, Olsen NJ. Use of P-31 magnetic resonance spectroscopy to detect metabolic abnormalities in muscles of patients with fibromyalgia. Arthritis Rheum 1998; 41: 406-13.

9. Jeschonneck M, Grohmann G, Hein G, Sprott H. Abnornal microcirculation and temperature in skin above tender points in patients with fibromyalgia. Rheumatology (Oxford) 2000; 39: 917-21.

10. Bradley LA, McKendree-Smith, Alarcón GS, Cianfrini LR. Is fibromyalgia a neurologic disease? Curr Pain Headheache Rep 2002; 6: 106-14.

11. Russel IJ. Advances in fibromyalgia: possible role for central neurochemicals. Am J Med Sci 1998; 315: 377-84.

12. Mountz JM, Bradley LA, Alarcón GS. Abnormal function activity of the central nervous system in fibromyalgia syndrome. Am J Méd Sci 1998; 315: 385-96.

13. Crofford LJ. Neuriendocrine abnormalities in fibromyalgia and related disords. Am J Méd Sci 1998; 315: 359-66.

14. Blanco LE, de Serres FJ, Fernandez-Bustillo E, Kassam DA, Abesú D, Rodriguez C, Torre JC. ibrAlpha 1-Antitrypsin and fibromyalgia: new data in favour of the inflammatory hypothesis of fibromyalgia. Med Hypotheses 2005; 64 (4): 759-69. 
15. Hernanz W, Valenzuela A, Quijada J, Garcia A, de la Iglesia JL, Gutierrez A, Povedano J, Moreno I, Sanchez B. Lymphocyte subpopulations in patientes with primary fibromyalgia. J Rheumatol 1994, 21 (11): 2122-4.

16. Holman AJ, Myers RR. A randomized, double-blind, placebo-controlled trial of pramipexole, a dopamine agonist, in patientes with fibromyalgia receiving concomitant medications. Arthritis Rheum 2005; 52 (8): 2495-505.

17. Atra, E; Pollak, D.F.,; Martinez, J.E. Fibromialgia: etiopatogenia e terapêutica. Rev Bras Reumatol, v.33, N. 2, P. 65-72, 1993

18. Clark SR, Jones KD, Burckhardt CS, Bennett R. Exercise for patients with fibromyalgia: risks versus benefits. Curr Rheumatol Rep 2001; 3: 135-40.

19. Meiworm L, Jakob E, Walçker UA, Peter HH, Keul J. Patientes with fibromyalgia benefit from aerobic endurance exercise. Clin Rheumatol 2000; 19 (4): 253-7.

20. Marques AP, Mendonça LLF, Cossermelli W. Alongamento muscular em pacientes com fibromialgia a partir de um trabalho de reeducação postural global (RPG). Rev Bras Reumatol 1994; 34: 232-4.

21. Mendonça LLF, Marques, AP, Matsutani LA, Ferreira EAG. Exercícios de alongamento para pacientes com fibromialgia. Rev Bras Reumatol 2002; 42: 49-50.

22. Sabbag L. M. S., Dourado M. P., Yasbek Jr P, Novo N. F., Kaziyma H. H. S., Miyashaki M. H., Battistella R.L. - Estudo ergométrico evolutivo de portadoras de fibromialgia primária em programa de treinamento cardiovascular supervisionado Acta Fisiátrica 2000, 7(1): 29-34.

23. Ramsay C, Moreland J, Ho M, Joyce S, Walker S, Pullar T. An observer-blinded comparison of supervised and unsupervised aerobic exercise regimens in fibromyalgia. Rheumatology (Oxford) 2000; 39: 501-5.

24. Gashu BM, Marques AP, Ferreira EAG, Matsutani LA. Eficácia da estimulação elétrica nervosa transcutânea (TENS) e dos exercícios de alongamento no alívio da dor e na melhora da qualidade de vida de pacientes com fibromialgia. Rev Fisioter Univ São Paulo 2001; 8: 57-64.

25. Matsutani LA. Eficácia de um programa de tratamento fisioterapêutico sobre a qualidade de vida de pacientes com fibromialgia. [Dissertação de mestrado] São Paulo: Universidade de São Paulo (USP), 2003.

26. Minhoto GR. Eficácia do biofeedback como terapêutica na fibromialgia [Tese de doutorado]. São Paulo: Universidade Federal de São Paulo (UNIFESP); 1999.

27. Martinez JE, Barauna Filho IS, Kubokawa KM, Cevasco G, Pedreira IS, Machado LAM. Avaliação da qualidade de vida de pacientes com fibromialgia através do "Medical Outcome 36 Item Short-Form Study". Rev Bras Reumatol 1999; 39: 31216.

28. Bennett R. Fibromyalgia and the disability dilemma. Arthristis Rheum 1996; 39: 1627-34. 
29. White, KP, Speechley, M Harth, M, Ostbye, T. Comparing self-reported function and work disability in 100 community cases of fibromyalgia syndrome versus controls in london, Ontario. Arthristis Rheum 1999; 42:76-83.

30. Melzack R, Wall PD. Pain Mechanism: a new theory. Science, 1965:150:971-978.

31. Kitchen S \& Bazin S. Eletroterapia de Clayton. São Paulo: Ed Manole LTdA, 1998, p.80-86, 276-294.

32. Gersh, MR, Electrotherapy in Rehabilitation, Philadelphia: Ed. F.A. Davis Company, 1992, p. 149-197.

33. Mannheimer, C \& Carlsson, C.A. The analgesic effect of transcutaneous electrical nerve stimulation in patients with rheumatoid arthritis:A comparative study of pulse patterns. Pain 1979; 6: 329.

34. Lindsay DM, Dearness J, McGinley CC. Electrotherapy usage in private physiotherapy practice in Alberta. Physiother Can 1995; 47(1): 30-4.

35. Chabal C, Fishbain DA, Weaver M, Heine LW. Long-term transcutaneous electrical stimulation (TENS) use: impact on medication utilization and physical therapy costs. Clin J Pain 1998; 14(1): 66-73.

36. Sherry JE; Oehrlein KM; Hegge KS; Morgan BJ. Effect of burst-mode transcutaneous electrical nerve stimulation on peripheral vascular resistence. Phys Ther 2001; 81 (6): 1183-91.

37. Cheing GL, HulChan CW, Chan KM. Does four weeks of TENS and/or isometric exercise cumulative reduction of osteoarthritic knee pain? Clin Rehabil 2002; 16(7): 749-60.

38. Rushton DN. Electrical stimulation in the treatment of pain. Disabil Rehabil 2002; 24(8): 407-15.

39. Limoge A. Electricity in pain management. Presse Med 1999; 28(39): 2197-203.

40. Lampl C, Kreczi T, Klingler D. Transcutaneous electrical nerve stimulation in the treatment of chronic pain: predictive factors and evaluation of the method. Clin $\mathrm{J}$ Pain 1998; 14(2): 134-42.

41. Kruger LR, Van der Linder WJ, Cleaton-Jones PE. Transcutaneous electrical nerve stimulation in the treatment of myofascial pain dysfunction. S Afr J Surg 1998; 36(1): 35-8.

42. Fedorczk J. The role of physical agentes in modulating pain. J Hand Ther 1997; 10(2): 110-21.

43. Stone RG, Wharton RB. Simultaneous multiple-modality therapy for tension headheaches and neck pain. Biomed Instrum Technol 1997; 31(3): 259-62.

44. Bassan H, Niv D, Jourgenson U, Wientroub S, Spirer Z. Localized fibromyalgia in a child. Paediatr Anaesth 1995; 5(4): 263-5. 
45. Fenollosa P, Pallares J, Cervera J, Pelegrin F, Inigo V, Giner M, Forner V. Chronic pain in the spinal cord injured: statistical approach and pharmacological treatment. Paraplegia 1993; 31(1): 722-9.

46. Tulgar M. Advances in electrical nerve stimulation techiniques to manage chronic pain: an overview. Adv Ther 1992; 9(6): 366-72.

47. Ernst E. TENS: fcition and fact.Fortschr Med 1992; 110(26): 471-2.

48. Long DM. Fifteen year of transcutaneous electrical stimulation for pain control. Stereofact Funct Neurosurg 1991; 56(1): 2-19.

49. Barreto, JM, Silva, EDO, Sá, L Aplicação do estímulo elétrico transcutâneo e de ondas curtas nas algias da coluna vertebral. Rev Bras Cienc. Saúde 1997; 1:31-6.

50. Bassanta, AD, sproesser, JG, Paiva, G. Estimulação elétrica neural transcutânea (TENS): sua aplicação nas disfunções tempor omandibulares 1997; 11(2): 109-16.

51. Costa, CM, D'almeida, JAC. Efeito da estimulação elétrica analgésica transcutânea sobre algumas síndromes de dor crônica: análise de 74 casos. Rev Bras Neurologia, 1991; 27(3): 99-101.

52. Costa, RM, Costa ML. Eletroestimulação transcutânea em pacientes idosos com dor crônica articular. An. Brás. Gerontol, 1981; 3(2): 49-52.

53. Marques A P, Manual de Goniometria - $2^{\mathrm{a}}$ Edição, São Paulo: Manole, 2003.

54. Burckhardt CS, Clark SR, Bennett RM. The Fibromyalgia Impact Questionnaire: Development and Validation. J Rheumatol 1991; 18: 728-33

55. Ware JE, Sherborne CD. The MOS 36-item Short-Form Health Survey (SF-36). I. Conceptual framework and item selection. Med care 1992; 30: 473-83.

56. Pimenta Cam \& Teixeira M.J. Proposta de adaptação do questionário de dor McGill para a língua portuguesa. Rev Esc Enf USP 1996; 70: 473-83.

57. Fischer, A.A. Pressurealgometry over normal muscle. Standart values, validity and reproducibility of pressure threshold. Pain 1987;30: 115-26.

58. Huskinsson, ec. Measurement of pain. Lancet, 1974; 9: 1127-31.

59. Marques AP, Ferreira EAG, Matsutani LA, Pereira CAB, Assumpção A. Quantifying pain threshold and quality of life of fibromyalgia patients Clinical Rheumatology. 2005, 24(3): 266-271.

60. Ciconelli RM. Tradução para o português e validação do questionário genérico de avaliação da qualidade de vida "Medical Outcomes Study 36-Item Short-Form Health Survey (SF-36)" [Tese de Doutorado]. São Paulo: Universidade Federal de São Paulo (UNIFESP); 1997.

61. Marques AP, Rhoden L, Sique ira JO, João SMA. Pain evaluation of patientes with fibromyalgia, osteoarthritis and low back pain. Rev Hosp Clin Fac Med S Paulo 2001; 56: 5-10. 
62. Rollman GB. Measurement of pain in fibromyalgia in the clinic and laboratory. $\mathrm{J}$ Rheumatol 1989; 19: 113-119.

63. LittleJohn G. A database for fibromyalgia. Rheum Dis Clin North Am 1995; 21: 527-541.

64. Ferreira, E.A.G., Marques, A. P., Matsutani, L. A., Vasconcellos, E. G., de Mendonça, L.L.F. Avaliação da dor e estresse em pacientes com fibromialgia. Rev Bras Reumatol 2002; 42(2): 104-10.

65. Mello M, A imagem corporal na fibromialgia, sua relação com a postura antálgica. [Monografia de conclusão de curso]. São Paulo: 1995.

66. Kendall FP, McCreary EK, Provance PG. Músculos. Provas e funções. São Paulo: Manole; 1985.

67. Jacob Filho, W. Atividade física e envelhecimento saudável. [Tese de Doutorado]. São Paulo: Universidade de São Paulo (USP); 2004.

68. Riemsma RP, Taal E, Kirwan JR, Rasker JJ. Patient education programmes for adults with rheumatoid arthritis. BMJ 2002; 325: 558-9.

69. Keel PJ, Bodoky C, Gerhard U, Müller W. Comparison of integrated group therapy and group relaxation training for fibromyalgia. Clin J Pain 1998; 14: 232-8. 
ANEXO 1 


\section{ANEXO 2}

\section{FISIOTERAPIA}

\section{Protocolo de Avaliação: Fibromialgia}

Data: / $/ 200$

\section{1- DADOS DO(A) PACIENTE:}

\begin{tabular}{|c|c|c|c|}
\hline Idade: & Sexo: & Cor: & \\
\hline Peso: & Altura: & IMC: & $\mathrm{Kg} / \mathrm{m}^{2}$ \\
\hline \multicolumn{4}{|c|}{\begin{tabular}{l|l} 
Profissão Atual: & Profissão Anterior:
\end{tabular}} \\
\hline \multicolumn{4}{|c|}{$\begin{aligned} & \text { Nível de escolaridade: ( )Sem estudo }(\text { ( }) 1^{\circ} \text { grau incompleto } \\
&(\text { ( }) 2^{\circ} \text { grau incompleto }(\text { ( }) 2^{\circ} \text { grau completo } \\
&\end{aligned}$} \\
\hline Estado Civil: ( )Casado(a) & ( )Solteiro(a) & parado(a) & ( )Viúvo(a) \\
\hline \multicolumn{4}{|l|}{ Diagnóstico Médico: } \\
\hline Medicamentos em uso: & & & \\
\hline
\end{tabular}

2- HISTÓRIA (Tempo de dor/ local da dor em ordem decrescente de intensidade/ período do dia em que a dor é mais intensa/ melhora ou piora da dor/ qualidade do sono e tipo de colchão e travesseiro).

Quantos dias da semana você precisa tomar remédio para sentir-se melhor?

\section{3- ESCALA ANALÓGICA VISUAL DA DOR}

"Marque na linha abaixo onde está a dor que você está sentindo agora."

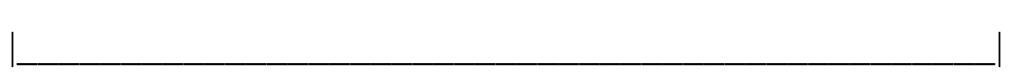

Sem dor

Dor insuportável 
4- LIMIAR DA DOR NOS TENDER POINTS:

\begin{tabular}{|c|c|l|}
\hline $\mathrm{D}$ & $\mathrm{E}$ & \multicolumn{1}{c|}{ tender points } \\
\hline & & Base do occipital \\
\hline & & Cervical baixa anterior entre C5-C7 \\
\hline & & Trapézio \\
\hline & & Supraespinhoso \\
\hline & & Segunda articulação costocondral \\
\hline & & Epicôndilo lateral \\
\hline & & Glúteos \\
\hline & & Trocânter maior \\
\hline & & Borda medial dos joelhos \\
\hline
\end{tabular}

\section{5- AVALIAÇÃO QUALITATIVA DAS CADEIAS MUSCULARES:}

I. Aspecto que mais lhe chama a atenção na postura do indivíduo:

\section{Cadeia inspiratória:}

a) Padrão postural:

$\begin{array}{cccc}\text { Ombros } & \text { Cabeça } & \text { Toráx em } & \text { Aumento da } \\ \text { protraídos } & \text { anteriorizada } & \text { posição } & \text { lordose } \\ (\quad) & (\text { ) } & \text { inspiratória ( ) } & \text { lombar ( ) }\end{array}$

b) avaliação:

\section{Cadeia posterior:}

a) Padrão postural:

$\begin{array}{lcccc}\text { Ângulo } & \text { Joelhos } & \text { Joelhos } & \text { Curvas } & \text { Ângulo } \\ \text { tíbio-társico } & \text { em flexão } & \text { valgos } & \text { Vertebrais } & \text { Coxo- } \\ \text { aberto }(\text { ) } & (\text { ) } & \text { ou } & \text { acentuadas ou } & \text {-femural } \\ & & \text { varos( ) } & \text { retificadas ( ) } & \text { aberto (...) } \\ \text { b) avaliação: } & & & & \end{array}$


III. Cadeia ântero-interna da bacia:

a) padrão postural
Aumento da
Flexão do quadril
Rotação medial e
Joelhos valgos
lordose lombar
( )
adução do quadril
( )
b) avaliação:

\section{Cadeia anterior do braço:}

a) padrão postural:

$\begin{array}{ccccc}\begin{array}{c}\text { Ombros } \\ \text { elevados }\end{array} & \begin{array}{c}\text { Abdução e } \\ \text { flexão dos } \\ \text { ombros ( })\end{array} & \begin{array}{c}\text { Flexão de } \\ \text { cotovelos }\end{array} & \begin{array}{c}\text { Pronação } \\ \text { de }\end{array} & \begin{array}{c}\text { Flexão de } \\ \text { punhos e } \\ \text { antebraços }\end{array} \\ \text { b) avaliaçãos: } & \left(\begin{array}{c}\text { dedos ( ) }\end{array}\right.\end{array}$

V. Cadeia ântero-interna do ombro:
a) padrão postural:
adução e rotação medial de ombro ( )
b) avaliação:

\section{6- TESTES DE FLEXIBILIDADE:}

\begin{tabular}{|l|l|l|}
\hline Schober $(\mathrm{cm})$ & Stibor $(\mathrm{cm})$ & Terceiro dedo-chão $(\mathrm{cm})$ \\
\hline & & \\
\hline
\end{tabular}


ANEXO 3

QUESTIONÁRIO DO IMPACTO DA FIBROMIALGIA (FIQ):

\begin{tabular}{|lcccc|}
\hline 1. O que você é capaz de fazer? & sempre & muitas vezes & ocasionalmente & nunca \\
a) Fazer compras & 0 & 1 & 2 & 3 \\
b) Lavar e estender roupa & 0 & 1 & 2 & 3 \\
c) Cozinhar & 0 & 1 & 2 & 3 \\
d) Lavar a louça & 0 & 1 & 2 & 3 \\
e) Passar aspirador no tapete & 0 & 1 & 2 & 3 \\
f) Arrumar a cama & 0 & 1 & 2 & 3 \\
g) Caminhar vários quarteirões & 0 & 1 & 2 & 3 \\
h) Visitar os amigos & 0 & 1 & 2 & 3 \\
i) Trabalhar fora & 0 & 1 & 2 & 3 \\
j) Dirigir carro & 0 & 1 & 2 & 3 \\
\hline
\end{tabular}

2. Dos sete dias da última semana, quantos dias sentiu-se bem?
$\begin{array}{lllllll}1 & 2 & 3 & 4 & 5 & 6 & 7\end{array}$

3. Quantos dias da última semana faltou ao trabalho por causa da fibromialgia? (Se não tiver um emprego, deixa este item em branco)

$\begin{array}{lllll}1 & 2 & 3 & 4 & 5\end{array}$

4. No trabalho, quanto a dor ou outros sintomas da fibromialgia interferem na habilidade de trabalhar?

nenhum problema

grande dificuldade

5. Como tem sido a intensidade da sua dor?

sem dor

dor muito severa

6. Como tem sido a intensidade do seu cansaço?

sem cansaço

7. Como você se sente quando acorda pela manhã?

muito cansado

acordo bem

acordo muito cansado

8 . Você sente rigidez?

não sinto rigidez

muita rigidez

9. Você sente tensão, nervosismo ou ansiedade?

nenhuma tensão

muita tensão

10. Você se sente deprimido ou triste? 


\section{ANEXO 4}

\section{QUESTIONÁRIO SF-36:}

INSTRUÇÕES: Esta pesquisa questiona você sobre sua saúde. Estas informações nos manterão informados de como você se sente e quão bem você é capaz de fazer atividades de vida diária. Responda cada questão marcando a resposta como indicado. Caso você esteja inseguro em como responder, por favor, tente responder o melhor que puder.

1. Em geral, você diria que sua saúde é:

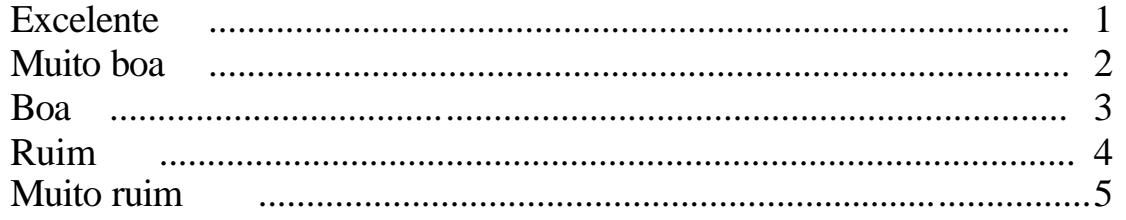

2. Comparada há um ano atrás, como você classificaria sua saúde em geral, agora?

Muito melhor agora do que há um ano atrás

(circule uma)

Um pouco melhor agora do que há um ano atrás 1

Quase a mesma coisa do que há um ano atrás 2

Um pouco pior agora do que há um ano atrás.

Muito pior agora do que há um ano atrás 5

3. Os seguintes itens são sobre atividades que você poderia fazer atualmente durante um dia comum.

Devido à sua saúde, você tem dificuldades para fazer essas atividades? Neste caso, quanto?

(circule um número em cada linha)

\begin{tabular}{|l|c|c|c|}
\hline Atividades & $\begin{array}{c}\text { Sim. } \\
\text { Dificulta muito }\end{array}$ & $\begin{array}{c}\text { Sim. } \\
\text { Dificulta pouco }\end{array}$ & $\begin{array}{c}\text { Não. } \\
\text { Não dificulta de } \\
\text { modo algum }\end{array}$ \\
\hline $\begin{array}{l}\text { A) Atividades vigorosas, que exigem muito } \\
\text { esforço, tais como correr, levantar objetos } \\
\text { pesados, participar de esportes árduos }\end{array}$ & 1 & 2 & 3 \\
\hline $\begin{array}{l}\text { B) Atividades moderadas, tais como mover } \\
\text { uma mesa, passar aspirador de pó, jogar bola, } \\
\text { varrer casa }\end{array}$ & 1 & 2 & 3 \\
\hline C) Levantar ou carregar mantimentos & 1 & 2 & 3 \\
\hline D) Subir vários lances de escada & 1 & 2 & 3 \\
\hline E) Subir um lance de escadas & 1 & 2 & 3 \\
\hline F) Curvar-se, ajoelhar-se ou dobrar-se & 1 & 2 & 3 \\
\hline G) Andar mais de 1 Km & 1 & 2 & 3 \\
\hline H) Andar vários quarteirões & 1 & 2 & 3 \\
\hline I) Andar um quarteirão & 1 & 2 & 3 \\
\hline J) Tomar banho ou vestir-se & 1 & 2 & 3 \\
\hline
\end{tabular}


4. Durante as útimas 4 semanas, você teve algum dos seguinte problemas com o seu trabalho ou com alguma atividade diária regular, como consequência de sua saúde física?

(circule um número em cada linha)

\begin{tabular}{|c|c|c|}
\hline & Sim & Não \\
\hline $\begin{array}{l}\text { A) Você diminuiu a quantidade de tempo que dedicava ao seu } \\
\text { trabalho ou a outras atividades? }\end{array}$ & 1 & 2 \\
\hline B) Realizou menos tarefas do que gostaria? & 1 & 2 \\
\hline C) Esteve limitado no seu tipo de trabalho ou em outras atividades? & 1 & 2 \\
\hline $\begin{array}{l}\text { D) Teve dificuldade para fazer seu trabalho ou outras atividades } \\
\text { (p.ex.: necessitou de um esforço extra)? }\end{array}$ & 1 & 2 \\
\hline
\end{tabular}

5. Durante as últimas 4 semanas, você teve algum dos seguintes problemas com o seu trabalho ou com outra atividade regular diária, como consequência de algum problema emocional (como sentirse deprimido ou ansioso)?

(circule um número em cada linha)

\begin{tabular}{|c|c|c|}
\hline & Sim & Não \\
\hline $\begin{array}{l}\text { A) Você diminuiu a quantidade de tempo que se dedicava ao seu } \\
\text { trabalho ou a outras atividades? }\end{array}$ & 1 & 2 \\
\hline B) Realizou menos tarefas do que gostaria? & 1 & 2 \\
\hline $\begin{array}{l}\text { C) Não trabalhou ou não fez qualquer das atividades com tanto } \\
\text { cuidado como geralmente faz? }\end{array}$ & 1 & 2 \\
\hline
\end{tabular}

6. Durante as últimas 4 semanas, de que maneira sua saúde física ou problemas emocionais interferem nas suas atividades sociais normais, em relação à família, vizinhos, amigos ou em grupo?

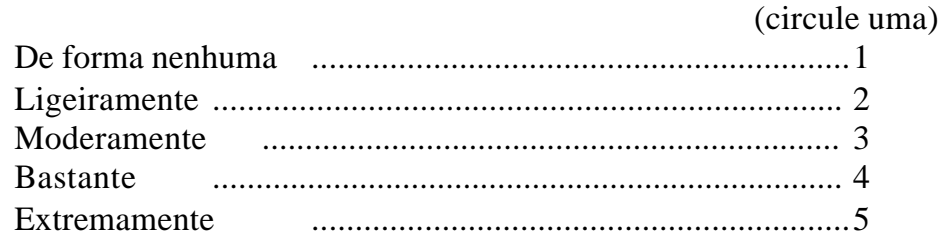

7. Quanta dor no corpo você teve durante as últimas 4 semanas ?

Nenhuma

(circule uma)

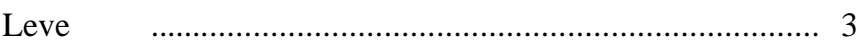

Moderada ................................................................. 4

Grave ............................................................... 5

Muito grave

8. Durante as últimas 4 semanas, quanto a dor interferiu com o seu trabalho normal (incluindo tanto trabalho fora ou dentro de casa)?

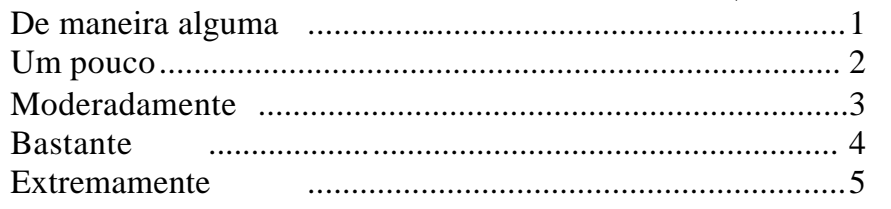


9. Estas questões são sobre como você se sente e como tudo tem acontecido com você durante as últimas 4 semanas. Para cada questão, por favor dê uma resposta que mais se aproxime da maneira como você se sente.

(circule um número para cada linha)

\begin{tabular}{|l|c|c|c|c|c|c|}
\hline & $\begin{array}{c}\text { Todo o } \\
\text { tempo }\end{array}$ & $\begin{array}{c}\text { A maior } \\
\text { parte do } \\
\text { tempo }\end{array}$ & $\begin{array}{c}\text { Uma } \\
\text { boa } \\
\text { parte do } \\
\text { tempo }\end{array}$ & $\begin{array}{c}\text { Alguma } \\
\text { parte do } \\
\text { tempo }\end{array}$ & $\begin{array}{c}\text { Uma } \\
\text { pequena } \\
\text { parte do } \\
\text { tempo }\end{array}$ & Nunca \\
\hline $\begin{array}{l}\text { A) Quanto tempo você tem se sentido } \\
\text { cheio de vigor, cheio de vontade, } \\
\text { cheio de força? }\end{array}$ & 1 & 2 & 3 & 4 & 5 & 6 \\
\hline $\begin{array}{l}\text { B) Quanto tempo você tem se sentido } \\
\text { uma pessoa muito nervosa? }\end{array}$ & 1 & 2 & 3 & 4 & 5 & 6 \\
\hline $\begin{array}{l}\text { C) Quanto tempo você tem se sentido } \\
\text { tão deprimido que nada pode } \\
\text { animá-lo? }\end{array}$ & 1 & 2 & 3 & 4 & 5 & 6 \\
\hline $\begin{array}{l}\text { D) Quanto tempo você tem se sentido } \\
\text { calmo ou tranquilo? }\end{array}$ & 1 & 2 & 3 & 4 & 5 & 6 \\
\hline $\begin{array}{l}\text { E) Quanto tempo você tem se sentido } \\
\text { com muita energia? }\end{array}$ & 1 & 2 & 3 & 4 & 5 & 6 \\
\hline $\begin{array}{l}\text { F) Quanto tempo você tem se sentido } \\
\text { desanimado e abatido? }\end{array}$ & 1 & 2 & 3 & 4 & 5 & 6 \\
\hline $\begin{array}{l}\text { G) Quanto tempo você tem se sentido } \\
\text { esgotado? }\end{array}$ & 1 & 2 & 3 & 4 & 5 & 6 \\
\hline $\begin{array}{l}\text { H) Quanto tempo você tem se sentido } \\
\text { uma pessoa feliz? }\end{array}$ & 1 & 2 & 3 & 4 & 5 & 6 \\
\hline $\begin{array}{l}\text { I) Quanto tempo você tem se sentido } \\
\text { cansado? }\end{array}$ & 1 & 2 & 3 & 4 & 5 & 6 \\
\hline
\end{tabular}

10. Durante as últimas 4 semanas, quanto do seu tempo a sua saúde física ou problemas emocionais interferiram em suas atividades sociais (como visitar amigos, parente, etc...)?

(circule uma)

Todo o tempo $\quad$......................................................... 1

A maior parte do tempo ................................................. 2

Alguma parte do tempo ................................................. 3

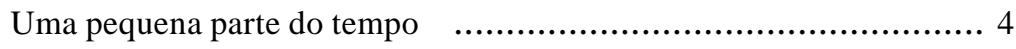

Nenhuma parte do tempo $\quad$.............................................. 5

11. O quanto verdadeiro ou falso é cada uma das afirmações para você?

\begin{tabular}{|c|c|c|c|c|c|}
\hline & $\begin{array}{c}\text { Definitivamen } \\
\text { verdadeiro }\end{array}$ & $\begin{array}{r}\text { A maioria } \\
\text { das vezes } \\
\text { verdadeiro }\end{array}$ & Não sei & $\begin{array}{c}\text { A maioria } \\
\text { das vezes } \\
\text { falsa }\end{array}$ & $\begin{array}{c}\text { Definitivamen } \\
\text { falsa }\end{array}$ \\
\hline $\begin{array}{l}\text { A) Eu costumo adoecer um pouco mais } \\
\text { facilmente que as outras pessoas }\end{array}$ & 1 & 2 & 3 & 4 & 5 \\
\hline $\begin{array}{l}\text { B) Eu sou tão saudável quanto qualquer } \\
\text { pessoa que eu conheço }\end{array}$ & 1 & 2 & 3 & 4 & 5 \\
\hline C) Eu acho que a minha saúde vai piorar & 1 & 2 & 3 & 4 & 5 \\
\hline D) Minha saúde é excelente & 1 & 2 & 3 & 4 & 5 \\
\hline
\end{tabular}


ORIENTAÇÕES PARA PONTUAÇÃO DO SF-36

\begin{tabular}{|c|c|c|c|c|}
\hline Questão & \multicolumn{4}{|c|}{ Pontuação } \\
\hline 01 & $1 ? 5.0$ & $3 ? \quad 3.4$ & $4 ? 2.0$ & $5 ? \quad 1.0$ \\
\hline $\mathbf{0 3}$ & \multicolumn{4}{|c|}{ Soma normal } \\
\hline 04 & \multicolumn{4}{|c|}{ Soma normal } \\
\hline 05 & \multicolumn{4}{|c|}{ Soma normal } \\
\hline 06 & $1 ? 5$ & $2 ? 4$ & $4 ? 2$ & $5 ? 1$ \\
\hline 07 & $1 ? \quad 6.0$ & $2 ? 4.4$ & $4 ? 3.1$ & $5 ? \quad 2.2$ \\
\hline 08 & \multicolumn{4}{|c|}{ 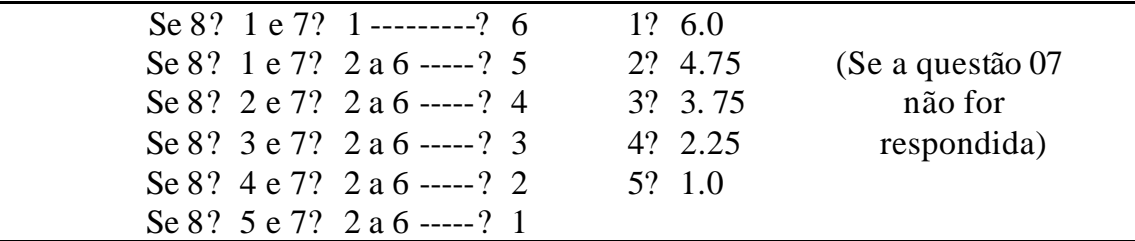 } \\
\hline 09 & \multicolumn{4}{|c|}{$\begin{array}{l}\text { A,D,E, } \mathrm{H}=\text { valores contrários }(1=6,2=5,3=4,4=3,5=2 \text { e } 6=1) \\
\text { Vitalidade }=A=E=G=I \\
\text { Saúde Mental }=B=C=D=F=H\end{array}$} \\
\hline 10 & \multicolumn{4}{|c|}{ Soma norma 1} \\
\hline 11 & \multicolumn{4}{|c|}{$\begin{array}{l}\text { Soma de: } \\
\text { A + C (valores normais) } \\
\text { B + D (valores contrários: } 1=6,2=5,3=4,4=3,5=2 \text { e } 6=1 \text { ) }\end{array}$} \\
\hline
\end{tabular}

\begin{tabular}{|l|c|c|c|}
\hline \multicolumn{1}{|c|}{ Item } & Questão & Limites & $\begin{array}{c}\text { Score Range } \\
\text { (variação) }\end{array}$ \\
\hline Capacidade Funcional & 3 & 10,30 & 20 \\
\hline Aspecto Físico & 4 & 4,8 & 4 \\
\hline Dor & $7+8$ & 2,12 & 10 \\
\hline Estado Geral de Saúde & $1+11$ & 5,25 & 20 \\
\hline Vitalidade & $9 \mathrm{~A}, \mathrm{E}, \mathrm{G}, \mathrm{I}$ & 4,24 & 20 \\
\hline Aspectos Sociais & $6+10$ & 2,10 & 8 \\
\hline Aspecto Emocional & 5 & 3,6 & 3 \\
\hline Saúde Mental & $9 \mathrm{~B}, \mathrm{C}, \mathrm{D}, \mathrm{F}, \mathrm{H}$ & 5,30 & 25 \\
\hline
\end{tabular}

Row Scale:

Ex: Item $=[$ Valor obtido - Valor mais baixo $] \times 100$

$$
\text { Variação }
$$

Ex: $\quad$ Capacidade Funcional $=21$

Valor mais baixo $=10$

Variação $=20$

$\underline{21-10} \times 100=55$

20

Dados Perdidos:

Se responder a mais de $\mathbf{5 0 \%}=$ substituir pela média

$0=$ pior escore $\quad 100=$ melhor escore 


\section{ANEXO 5}

\section{Questionário de Dor de McGill (adaptado para língua portuguesa)}

Escolha as palavras que melhor descrevem a sua dor atual. Não escolha aquelas que não se aplicam ao seu caso. Escolha somente uma palavra de cada grupo.

\begin{tabular}{|c|c|c|c|c|}
\hline $\mathbf{1}$ & 5 & 9 & 13 & 17 \\
\hline 1-vibração & 1-beliscão & 1-mal localizada & 1-castigante & 1-espalha \\
\hline 2-tremor & 2-aperto & 2-dolorida & 2-atormenta & 2-irradia \\
\hline 3-pulsante & 3-mordida & 3-machucada & 3-cruel & 3-penetra \\
\hline 4-latejante & 4-cólica & 4-doída & & 4-atravessa \\
\hline 5-como batida & 5-esmagamento & 5-pesada & & \\
\hline \multicolumn{5}{|l|}{ 6-como pancada } \\
\hline 2 & 6 & $\mathbf{1 0}$ & 14 & 18 \\
\hline 1-pontada & 1-fisgada & 1-sensível & 1-amedrontadora & 1-aperta \\
\hline 2-choque & 2-puxão & 2-esticada & 2-apavorante & 2 -adormece \\
\hline \multirow[t]{3}{*}{ 3-tiro } & 3-em torção & 3-esfolada & 3-aterrorizante & 3-repuxa \\
\hline & & 4-rachando & 4-maldita & 4-espreme \\
\hline & & & 5-mortal & 5-rasga \\
\hline 3 & 7 & 11 & 15 & 19 \\
\hline 1-agulhada & 1-calor & 1-cansativa & 1-miserável & 1-fria \\
\hline 2-perfurante & 2-queimação & 2-exaustiva & 2-enlouquecedora & 2-gelada \\
\hline 3-facada & 3 -fervente & & & 3-congelante \\
\hline 4-punhalada & 4-em brasa & & & \\
\hline \multicolumn{5}{|l|}{ 5-em lança } \\
\hline 4 & 8 & 12 & 16 & 20 \\
\hline 1-fina & 1-formigamento & 1-enjoada & 1-chata & 1-aborrecida \\
\hline 2-cortante & 2-coceira & 2-sufocante & 2-que incomoda & 2-dá náusea \\
\hline \multirow[t]{3}{*}{ 3-estraçalha } & 3 -ardor & & 3-desgastante & 3-agonizante \\
\hline & 4-ferroada & & 4-forte & 4-pavorosa \\
\hline & & & 5-insuportável & 5-torturante \\
\hline
\end{tabular}

\begin{tabular}{|lr|}
\hline Dimensão sensitiva & $1-10$ \\
Dimensão afetiva & $11-15$ \\
Dimensão avaliativa & 16 \\
Miscelânea & $17-20$ \\
\hline
\end{tabular}




\author{
ANEXO 6 \\ HOSPITAL DAS CLÍNICAS \\ DA
}

FACULDADE DE MEDICINA DA UNIVERSIDADE DE SÃO PAULO

TERMO DE CONSENTIMENTO LIVRE E ESCLARECIDO

I - DADOS DE IDENTIFICAÇÃO DO SUJEITO DA PESQUISA OU RESPONSÁVEL LEGAL
1.
NOME
DO
PACIENTE
DOCUMENTO DE IDENTIDADE No :
SEXO: .M ( ) F ( )
DATA NASCIMENTO:
$\mathrm{N}^{\mathrm{o}}$
APTO:
BAIRRO:
CIDADE

CEP: TELEFONE: DDD ( )

2.RESPONSÁVEL

LEGAL

NATUREZA (grau de parentesco, tutor, curador etc.)

DOCUMENTO DE IDENTIDADE : SEXO: $M(\quad) \quad F(~)$

DATA NASCIMENTO.: .....................

ENDEREÇO

$\mathrm{N}^{\circ}$

APTO:

BAIRRO:

CIDADE:

CEP:

TELEFONE:

DDD

\title{
II - DADOS SOBRE A PESQUISA CIENTÍFICA
}

1. TÍTULO DO PROTOCOLO DE PESQUISA:

Efeitos de um programa fisioterapêutico na melhora da sintomatologia e qualidade de vida de pacientes com fibromialgia

PESQUISADOR: FERNANDA CARBONARIO

CARGO/FUNÇÃO: FISIOTERAPEUTA

INSCRIÇÃO CONSELHO REGIONAL No CREFITO-3/ 27767-F 
UNIDADE DO HCFMUSP: FISIOPATOLOGIA EXPERIMENTAL

3. AVALIAÇÃO DO RISCO DA PESQUISA:

（ ） SEM RISCO (X) RISCO MÍNIMO （） RISCO MÉDIO

( ) RISCO BAIXO （） RISCO MAIOR

(probabilidade de que o indivíduo sofra algum dano como conseqüência imediata ou tardia do estudo)

4.DURAÇÃO DA PESQUISA : 2 anos

\section{III - REGISTRO DAS EXPLICAÇÕES DO PESQUISADOR AO PACIENTE OU SEU REPRESENTANTE LEGAL SOBRE A PESQUISA, CONSIGNANDO:}

1. Este estudo visa encontrar maneiras alternativas para o tratamento da Fibromialgia;

2. Serão utilizados exercícios de alongamento muscular, exercícios de condicionamento (bicicleta ergométrica) e em alguns casos será utilizada uma corrente de estimulação elétrica, chamada TENS (estimulação elétrica nervosa transcutânea), que causa uma sensação de formigamento no local aplicado e que após o término do tempo de utilização (30 minutos) traz uma sensação de alívio da dor na região próxima ao local da aplicação. Para aplicação desta corrente será utilizado um aparelho que gera o pulso elétrico que é transmitido por um fio até os quatro eletrodos que são colocados na pele do paciente no ponto determinado pela fisioterapeuta e para que o elétrodo se fixe a pele é utilizado gel e fita crepe. O gel é utilizado somente para condução do estímulo elétrico e não contém substâncias que causem algum efeito;

3. A sensação de formigamento pode levar a um desconforto durante a aplicação para quem for sensível ao estímulo elétrico e após a aplicação o local de colocação dos eletrodos ficará levemente vermelho (hiperemia), o que passará após alguns minutos. Essa vermelhidão ocorre pelo aumento do fluxo sangüíneo no local da passagem da corrente elétrica;

4. Os benefícios que poderão ser obtidos são: alívio da dor, diminuição do cansaço e rigidez articular;

5. Além do recurso que será utilizado nessa pesquisa, há outras formas de tratamento que trazem benefícios aos pacientes com fibromialgia, entre eles destacam-se: a hidroterapia, a natação, a caminhada, os exercícios físicos de baixa intensidade e a acupuntura;

\section{IV - ESCLARECIMENTOS DADOS PELO PESQUISADOR SOBRE GARANTIAS DO SUJEITO DA PESQUISA:}

1. Você terra acesso, a qualquer tempo, às informações sobre procedimentos, riscos e benefícios relacionados à pesquisa, inclusive para esclarecer dúvidas. 
2.Você terá liberdade de retirar seu consentimento a qualquer momento e deixar de participar do estudo, sem que isto traga prejuízo à continuidade da assistência.

3. As informações obtidas no estudo serão confidenciais, sigilosas para garantirem sua privacidade.

4. O Hospital Geral de Pirajussara estará disponível para sua assistência caso ocorra eventuais danos à saúde, decorrentes da pesquisa.

5. Haverá viabilidade de indenização por eventuais danos à saúde decorrentes da pesquisa. 


\section{INFORMAÇÕES DE NOMES, ENDEREÇOS E TELEFONES DOS RESPONSÁ VEIS PELO ACOMPANHAMENTO DA PESQUISA, PARA CONTATO EM CASO DE INTERCORRÊNCIAS CLÍNICAS E REAÇÕES ADVERSAS.}

Profa Dra. Amélia Pasqual Marques

Endereço: Rua Cipotânea no 51Cidade universitária - SP/SP Fone: (11) 30917451

Fisioterapeuta Fernanda Carbonario

Av: Ibirama nº 1214 Jd Pirajussara - Taboão da Serra - SP Fone: (11) 41389483

VI. OBSERVAÇÕES COMPLEMENTARES :

\section{VII - CONSENTIMENTO PÓS-ESCLARECIDO}

Declaro que, após convenientemente esclarecido pelo pesquisador e ter entendido o que me foi explicado, consinto em participar do presente Protocolo de Pesquisa.

$$
\text { São Paulo, de }
$$

de 200 . 


\section{ANEXO 7}

Cartilha de Orientação as Pacientes com Fibromialgia 